\title{
Application of Al-Cu-W-Ta graded density impactors in dynamic ramp compression experiments
}

Cite as: J. Appl. Phys. 125, 145902 (2019); https://doi.org/10.1063/1.5055398

Submitted: 07 September 2018 . Accepted: 26 March 2019 . Published Online: 11 April 2019

James P. Kelly, Jeffrey H. Nguyen, Jonathan Lind, Minta C. Akin (D, Brian J. Fix, Cheng K. Saw, Elida R. White, Waldi O. Greene, Paul D. Asimow (D), and Jeffery J. Haslam
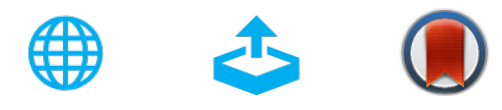

View Online

Export Citation

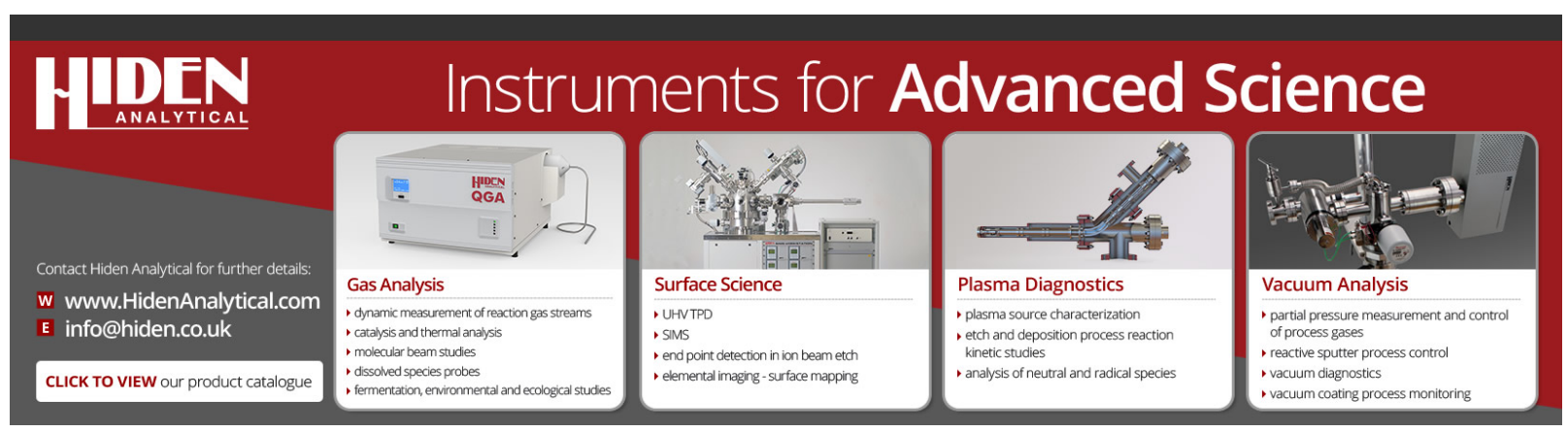




\title{
Application of Al-Cu-W-Ta graded density impactors in dynamic ramp compression experiments
}

\author{
Cite as: J. Appl. Phys. 125, 145902 (2019); doi: 10.1063/1.5055398 \\ Submitted: 7 September 2018 - Accepted: 26 March 2019 . \\ Published Online: 11 April 2019
}

James P. Kelly, ${ }^{1, a)}$ Jeffrey H. Nguyen, ${ }^{7}$ Jonathan Lind, ${ }^{7}$ Minta C. Akin, ${ }^{1}$ (D Brian J. Fix, ${ }^{7}$ Cheng K. Saw, ${ }^{1}$

Elida R. White, ${ }^{7}$ Waldi O. Greene, ${ }^{7}$ Paul D. Asimow, ${ }^{2}$ (D) and Jeffery J. Haslam ${ }^{1}$

\author{
AFFILIATIONS \\ ${ }^{1}$ Lawrence Livermore National Laboratory, Livermore, California 94551, USA \\ ${ }^{2}$ Division of Geological and Planetary Sciences, California Institute of Technology, Pasadena, California 91125, USA
}

a) Author to whom correspondence should be addressed: kelly70@llnl.gov

\begin{abstract}
Graded density impactors (GDIs) are used to dynamically compress materials to extreme conditions. Two modifications to a previously developed $\mathrm{Mg}-\mathrm{Cu}-\mathrm{W}$ GDI are made in this work before using it in a dynamic compression experiment: $\mathrm{Mg}$ is replaced with $\mathrm{Al}$ and a Ta disk is glued to the back. The Mg phase is replaced by Al because FCC Al remains solid to higher pressure along its Hugoniot compared to Mg. The addition of the Ta disk creates a constant particle velocity regime and facilitates a definition of peak pressure states. Microstructure analysis, profilometry, and ultrasonic C-scans of the Al-Cu-W GDI all confirm excellent uniformity. We evaluated signal variation in the radial direction of a dynamically compressed Al-LiF bilayer target to evaluate the contribution of spatial nonuniformity to errors. Velocity traces from five photon Doppler velocimetry (PDV) probes located at different radial distances from the center of the target varied at most by $1.1 \%$ with a root mean square of $0.3 \%$ during the compression ramp, demonstrating low PDV measurement error over a relatively large experimental area. The experimental PDV data also agrees well with 1D simulations that use inputs from predictive characterization models developed for the material properties resulting from tape casting, laminating, and powder consolidation processes. Low measurement error during quasiisentropic compression, leading to better precision, ensures a robust platform to reach extreme compression and low-temperature recovery states and facilitates discovery via synthesis, quenching, and preservation of new high-pressure phases.
\end{abstract}

Published under license by AIP Publishing. https://doi.org/10.1063/1.5055398

\section{INTRODUCTION}

Dynamic compression experiments are used to study matter at extreme conditions in fields as diverse as aerospace, biology, chemistry, geophysics, and planetary science. The physical state of matter in the Earth's core or the evolution of matter in a bolide impact target can be explored. ${ }^{1,2}$ An overview of the dynamic compression of materials that includes general considerations, experimental methods to generate dynamic compression, experimental diagnostics at high dynamic pressures, and error propagation is given elsewhere. ${ }^{3}$ Interesting chemistry and physics that emerge under extreme conditions are of general interest and have also been reviewed elsewhere.,

The report from the Basic Research Needs Workshop on Synthesis Science for Energy Relevant Technology ${ }^{4}$ identified four priority research directions (PRDs) for realizing the vision of predictive, science-directed synthesis. Two of the four PRDs are (1) to achieve mechanistic control of synthesis to access new states of matter and (2) to accelerate materials discovery by exploiting extreme conditions, complex chemistries and molecules, and interfacial systems. Many future discoveries are expected to come from relatively unexplored parameter spaces that push the boundaries of synthesis science. The latter PRD specifically highlights the ability to synthesize matter under extreme conditions, providing access to previously unknown phase space of new, metastable compounds. Shock physics and dynamic compression enable access to these extreme conditions for short periods of time, which may help quench new metastable phases. Nanosecond synthesis of diamond by shock compression is one of the most widely known examples of metastable phase synthesis, ${ }^{1}$ and other examples exist in the literature. Our 
recovery experiments after dynamic compression demonstrate a varying crystal defect structure evolution with loading paths, ${ }^{6}$ which could influence phase transitions.

The use of customized loading paths in dynamic compression, including intervals of quasi-isentropic compression, enables access to a wider range of extreme pressure and temperature conditions than can be achieved with traditional static or shock compression experiments. Compared to conventional shock compression, experiments with designed impedance profiles and ranges of impact velocity provide access to periods of quasi-isentropic compression that, in turn, allow temperature and pressure to be tuned, whichamong other applications-presents an exciting opportunity to quench new high-pressure phases to ambient conditions by exploiting lower temperatures that inhibit the kinetics of forward or backward transformations. Discovery and characterization of such novel recovered phases may have implications in condensed-matter physics, chemistry, materials science, planetary science, and various applications. Methods for achieving quasi-isentropic loading and other designed loading paths include gas gun, ${ }^{7-9}$ laser, ${ }^{10-12}$ and magnetically driven compression. ${ }^{13-17}$

Early quasi-isentropic compression experiments used cylindrical compression geometries, ${ }^{18-21}$ plane wave compressions with buffer layers, ${ }^{22-27}$ or conversion of a shock impact into a ramp before it enters the specimen. ${ }^{28,29}$ The use of a graded density impactor (GDI) for quasi-isentropic loading began with Barker ${ }^{30}$ in the 1980s. At that time, the fabrication of high-quality GDIs was recognized as the major challenge in creating quasi-isentropic compression with a well-controlled input wave. Tape casting, laminating, binder burnout, and hot pressing are highly effective methods of tailoring GDIs to control the thermodynamic path during an experiment because the GDI design can be controlled by the tape-stacking sequence. ${ }^{7,8,31-33}$ Such tailored GDIs can be designed to provide unique thermodynamic paths that include sequential combinations of shock, quasi-isentropic compression, constant pressure, and controlled release regimes-all in a single experiment-enabling mechanistic control of synthesis to access new states of matter.

The qualification of a new GDI design prepared by tape casting and laminating is lengthy and generally has three aspects. ${ }^{31-33}$ The first aspect is tape characterization, which is used to determine the tape-stacking sequence. As many as 100 tape layers stacked within a few millimeters may be required by the GDI design, which necessitates several months of characterization. Replication of qualification experiments can reduce common-cause variation (inherent process variation) and facilitate assigning and reducing special causes of variation, but at the expense of adding several more months onto the qualification time. GDI variation is of interest because a sensitivity study has demonstrated that pressure ramp uncertainty from the impactor is likely to generate more uncertainty in information extracted from dynamic ramp compression experiments than alignment and diagnostic uncertainties. ${ }^{34}$ The second and third aspects of qualification include process verification and deployment to verify that there are no processing or application-specific limitations.

High-impedance GDIs have recently been prepared by functionally grading $\mathrm{Mg}, \mathrm{Cu}$, and $\mathrm{W} .{ }^{33}$ In this work, we describe the fabrication and qualification of new high-impedance GDI prepared by functionally grading $\mathrm{Al}, \mathrm{Cu}$, and $\mathrm{W}$, followed by gluing Ta to the back of the GDI. One advantage of replacing $\mathrm{Mg}$ with $\mathrm{Al}$ is that the FCC Al phase melts at higher pressure along its Hugoniot compared to the HCP Mg phase. Microstructure analysis, ultrasonic C-scans, and profilometry of GDIs alongside photon Doppler velocimetry (PDV) signals recorded during a dynamic ramp compression experiment all confirm excellent GDI uniformity. Velocity traces from five PDV probes located at different radial distances from the center of a dynamically compressed target varied by less than $1.1 \%$ of nominal in the functionally graded section with a root mean square of $0.3 \%$, indicating low PDV measurement uncertainty. Low measurement uncertainty during quasi-isentropic compression, leading to better precision, ensures a robust experimental platform to facilitate the discovery and synthesis of new high-pressure phases that can be quenched to ambient conditions by exploiting extreme compression and lowtemperature recovery states.

\section{MATERIALS AND METHODS}

\section{A. Tape characterization and root cause analysis of variation}

At least 20 nominally two-phase metal composites spanning the full composition range of $\mathrm{Al}-\mathrm{Cu}$ and $\mathrm{Mg}-\mathrm{Cu}$ systems were fabricated by tape casting powder mixtures, stacking and laminating 50 layers of tapes, binder burnout, hot pressing, and characterization methods that have been described in detail. ${ }^{31-33}$ One of the systems consisted of aluminum (98\%, APS $10-14 \mu \mathrm{m}$, Alfa Aesar, Ward Hill, MA) and copper (99.9\%, 3-5 $\mu \mathrm{m}$, Alfa Aesar). The other system consisted of magnesium (99.8\%, -325 mesh, Alfa Aesar) and copper (99\%, -325 mesh, Alfa Aesar). The $\mathrm{Mg}-\mathrm{Cu}$ composites were prepared and characterized for comparison purposes.

The length of the binder burnout cycle was two days longer and the final temperature was $25^{\circ} \mathrm{C}$ higher (i.e., $400{ }^{\circ} \mathrm{C}$ ) for the $\mathrm{Al}-\mathrm{Cu}$ system compared to the binder burnout cycle for the $\mathrm{Mg}$-Cu system. The extended binder burnout cycle was necessary to prevent compact defects. All other parameters were controlled to the maximum extent possible. Samples were hot pressed at $370{ }^{\circ} \mathrm{C}$ for 66 min under a uniaxial stress of $250 \mathrm{MPa}$ using a Carver 30-ton Autoseries press (Carver, Wabash, IN). Tape layer thicknesses reported are the mean from measuring 5 blanks with a digital caliper. Consolidated layer thicknesses and composite densities were measured from the cylindrical geometry and masses of the hot pressed compacts. The $10-\mathrm{MHz}$ longitudinal acoustic velocities through the height of the compacts were measured in four approximately equidistant locations around the compact perimeter and in the center of the compact. A time-of-flight cross correlation method was used to calculate acoustic velocities. Reported values are an average of values obtained at the five measurement locations.

Three replicate samples of select $\mathrm{Mg}-\mathrm{Cu}$ composites $(n=3)$ were also prepared to evaluate the effect of secondary phases by X-ray diffraction (XRD) analysis and using Jade software (v.9.7, Materials Data, Inc., Livermore, CA). The XRD data were collected with a conventional Phillips vertical goniometer, utilizing $\mathrm{Cu}-\mathrm{K} \alpha$ radiation. Step scans were performed from $20^{\circ}$ to $100^{\circ} 2 \theta$ with a step size of $0.02^{\circ}$ and an acquisition time of $2 \mathrm{~s}$ per step. Rietveld refinement, ${ }^{35,36}$ a whole pattern fitting technique, was applied to the XRD data to extract estimates of the weight percentage of each 
phase with better accuracy than typical peak intensity comparison. The weight percent estimates were converted to volume percent using the theoretical density of the phases.

\section{B. GDI process verification}

An Al-Cu-W GDI was designed and built in two steps because of different processing requirements for $\mathrm{Al}-\mathrm{Cu}$ mixtures compared to $\mathrm{Cu}-\mathrm{W}$ mixtures, as noted by Yep et al. ${ }^{33}$ The $\mathrm{Cu}-\mathrm{W}$ tapes were prepared from $\mathrm{Cu}(1.5-5 \mu \mathrm{m}$, ACuPowder International, Union, NJ) and W $(99.9 \%, 1-5 \mu \mathrm{m}$, Alfa Aesar) and stacked in a compositional sequence that varied from $100 \% \mathrm{Cu}$ to a mixture of 50:50 volume percent $\mathrm{Cu}: \mathrm{W}$. This composition has impedance close to $\mathrm{Ta}$ and provides a good impedance match to the Ta disk that will be bonded to the back of the GDI. The binder burnout profile was similar in length to that of the $\mathrm{Al}-\mathrm{Cu}$ profile, but $50{ }^{\circ} \mathrm{C}$ lower (i.e., $350^{\circ} \mathrm{C}$ ). The samples were vacuum hot pressed in a graphite punch and die set for $2 \mathrm{~h}$ at $1000^{\circ} \mathrm{C}$ and $70 \mathrm{MPa}$ uniaxial stress (typical vacuum levels $10^{-5}-10^{-6}$ Torr). The $\mathrm{Al}-\mathrm{Cu}$ sequence, from $100 \% \mathrm{Al}$ to $100 \% \mathrm{Cu}$, was prepared as described in Sec. II A and hot pressed together with the finished $\mathrm{Cu}-\mathrm{W}$ sequence, arranged in the die, and hot pressed to bond the $\mathrm{Cu}-\mathrm{Cu}$ interface.

The Al-Cu-W GDI was characterized by surface profilometry with a wide-area 3D measurement system (VR 3100, KEYENCE Corporation, Itasca, IL). Ultrasonic testing with an UltraPAC ${ }^{\mathrm{TM}}$ instrument (UPK-T10, MISTRAS Group, Inc., Princeton, NJ) was conducted in the pulse-echo mode using a $15-\mathrm{MHz}$ transducer (0.375 in. diameter and 1.50 in. focal length) on a GDI immersed in mineral oil. The microstructure was also evaluated using standard microscopy techniques (sectioning, polishing, and imaging).

\section{GDI deployment}

A Ta disk was bonded to the back of a GDI fabricated by the procedure outlined in Sec. II B with STYCAST $^{\circledast}$ epoxy. The GDI and the Ta disk were firmly pressed into contact to squeeze out excess epoxy. The Ta disk-a high-purity, high-impedance metal standard in shock physics studies-provides a constant particle velocity regime after the ramped compression and prevents a release wave from interfering with the compression ramp. To assess the radial uniformity of a nominally $1 \mathrm{D}$ impact, one assembled GDI was mounted on a Lexan sabot and launched on the two-stage light gas gun facility at the California Institute of Technology (Shot \#530) to dynamically compress an aluminum target backed with a LiF window and observed by eight PDV probes located at different radial distances from the target center $(1,2,3,4,5,6,7$, and $8 \mathrm{~mm})$. A schematic of the experimental configuration is illustrated in Fig. 1. The edges were machined off the GDI to form a $25 \mathrm{~mm}$ diameter. The measured velocity of the projectile prior to impact by doubleflash X-ray and dual magnetic loop pickups was $3.85 \pm 0.04 \mathrm{~km} / \mathrm{s}$. Only PDV probes with response signal-to-noise ratios $(\mathrm{S} / \mathrm{N})$ greater than or equal to 5 were analyzed, corresponding to 5 out of 8 channels $(r=2,3,4,5,6 \mathrm{~mm})$, because smaller $\mathrm{S} / \mathrm{N}$ created discontinuities in the PDV trace when transforming the raw signals into particle velocities. Apparent velocities measured by PDV were corrected to account for $\mathrm{LiF}$ properties and give true velocities. ${ }^{37}$

Complementary simulations were performed to compare to experimental data and expand the opportunity for expedited GDI

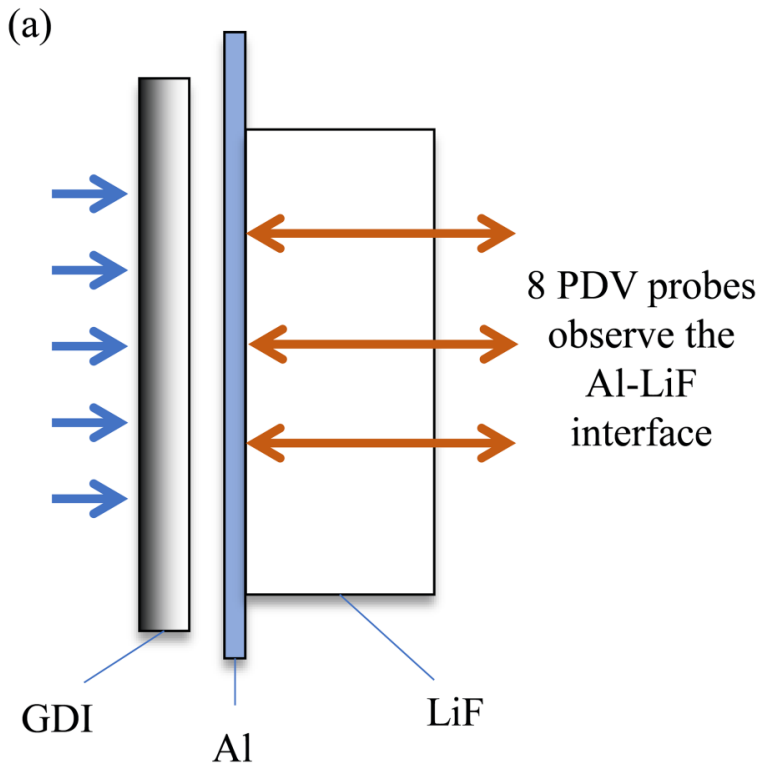

(b)

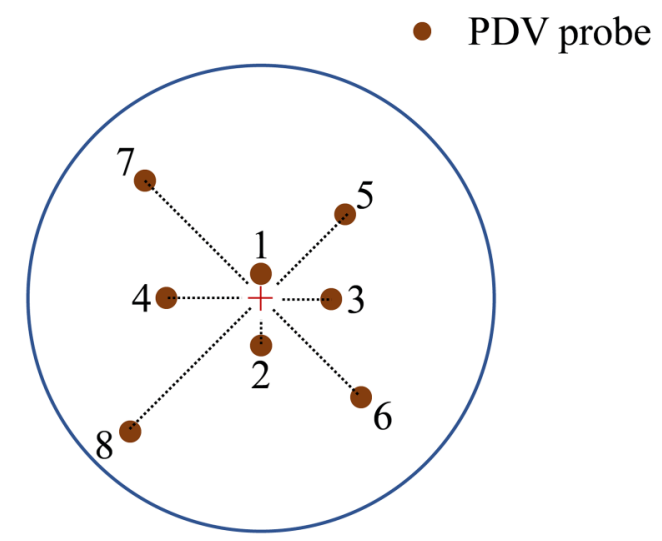

FIG. 1. (a) Side view schematic of a dynamic compression experiment where a 25-mm diameter GDI impacts a 32.5-mm diameter, 1.5-mm thick Al baseplate and a 19-mm diameter, 10-mm thick LiF window. (b) Back view schematic of the LiF window showing PDV probe locations that observe the Al-LiF interface at positions $1,2,3,4,5,6,7$, and $8 \mathrm{~mm}$ from the center.

development and qualification. Simulations were performed in ALE3D, a finite element code developed at the Lawrence Livermore National Laboratory. ${ }^{38}$ Inputs included model layer thicknesses and initial densities from tape characterization. A Mie-Grüneisen equation of state was used for all materials in the simulation with material parameters from Steinberg. ${ }^{39}$ Cubic hexahedral mesh elements were used with a side length of $200 \mathrm{~nm}$ resulting in $2 \times 2 \times 10^{5}$ elements. The time at impact was defined as $t=0 \mathrm{~ns}$ (shock breakout time and ramp compression times are relative to the impact time) and simulations continued up to $1 \mu \mathrm{s}$ after impact. Material composition of any given element was assigned based on probability equal to the volume fraction of constituents within a given layer in the GDI. 


\section{RESULTS AND DISCUSSION}

\section{A. Tape characterization and root cause analysis of variation}

Tape characterization for GDI qualification has been described elsewhere. ${ }^{31-33}$ Important characterization metrics include the consolidated thickness, density, and acoustic velocity. Layer thickness analysis for Al-Cu composites is shown in Fig. 2. The mean tape thickness is $81.12 \pm 0.06 \mu \mathrm{m}$ based on a $95 \%$ confidence interval [solid line in Fig. 2(a)] and the observed thickness range is within $\pm 8.09 \mu \mathrm{m}$ of the mean [bound by the dotted lines in Fig. 2(a)]. Figure 2(a) also demonstrates that the mean thickness, after binder burnout and consolidation, is $48.02 \pm 0.05 \mu \mathrm{m}$ based on a $95 \%$ confidence interval and the observed thickness range is within $\pm 7.99 \mu \mathrm{m}$ of the mean. Similar thickness variation from mean values (about $8 \mu \mathrm{m}$ ) and similar thickness variation patterns of the two data sets observed in Fig. 2(a) suggest that the consolidated thickness is correlated with tape thickness; this correlation is linear, as shown in Fig. 2(b). The consolidated
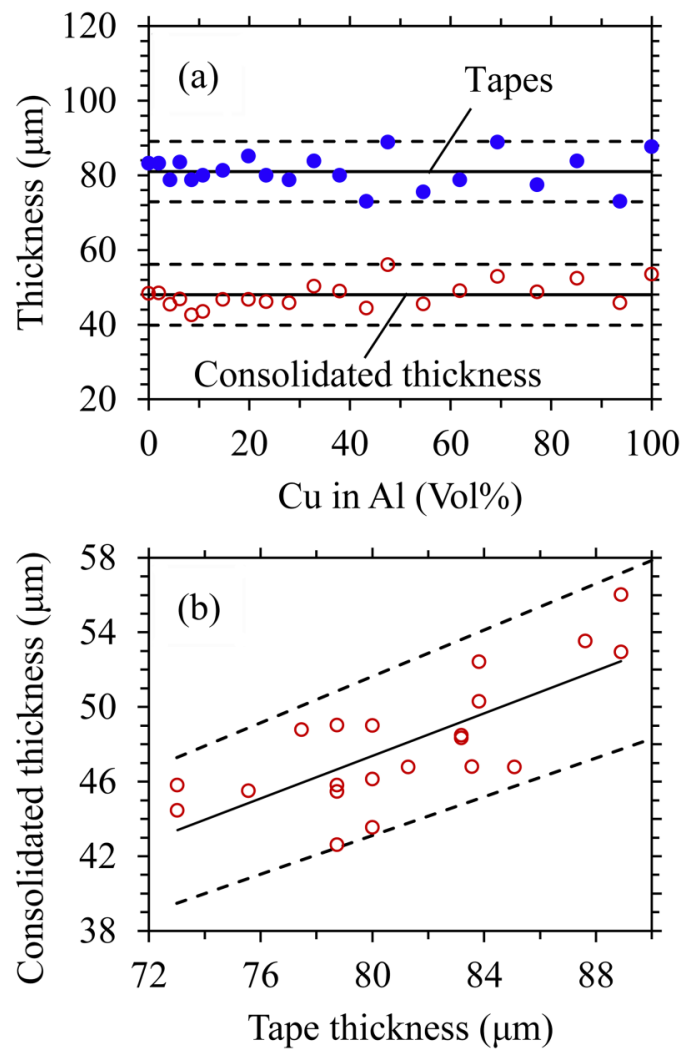

FIG. 2. (a) Experimental thicknesses of Al-Cu composite tapes (closed circles) and consolidated thickness (open circles). (b) Correlation between the Al-Cu tape thickness and the consolidated thickness $\left(R^{2}=0.56\right)$ that enables the prediction of consolidated layer thicknesses from the tape thickness measurements to within $\pm 9 \%$ of experimental observations. Mean thickness values or predictions (solid lines) and observed limits from the mean or predictions (dashed lines) are superimposed onto the plots. layer thickness can be predicted from the original tape thickness to within $\pm 9 \%$ based on this correlation.

Tape and consolidated thicknesses for $\mathrm{Mg}$ - $\mathrm{Cu}$ composites are shown in Fig. 3(a). The mean tape thickness is $85.16 \pm 0.08 \mu \mathrm{m}$
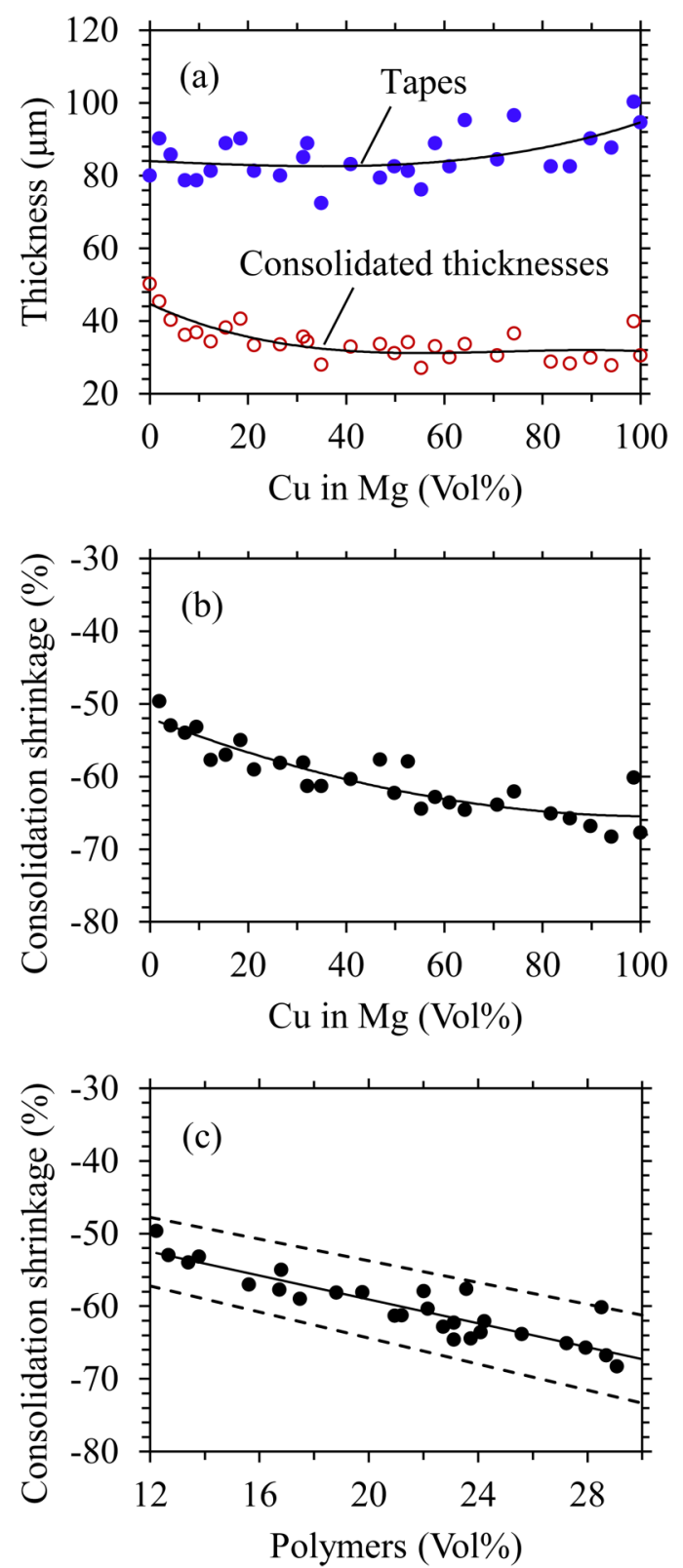

FIG. 3. (a) Experimental thicknesses of Mg-Cu composite tapes (closed circles) and consolidated thickness (open circles), (b) consolidated shrinkage of $\mathrm{Mg}-\mathrm{Cu}$ tapes, and $(c)$ correlation $\left(R^{2}=0.82\right)$ that enables the prediction of the consolidated layer thickness from tape thickness measurements and knowledge of the tape formulation to within $\pm 9 \%$ of experimental observations. A predicted consolidation shrinkage line (solid line) and observed limits from the prediction (dashed lines) are superimposed onto the correlation plot in (c). 
based on a $95 \%$ confidence interval and the observed thickness range is within $\pm 15.17 \mu \mathrm{m}$ of the mean. The average consolidated thickness is $34.31 \pm 0.06 \mu \mathrm{m}$ based on a $95 \%$ confidence interval and the observed thickness range is within $\pm 15.95 \mu \mathrm{m}$ of the mean. The observed thickness range is about twice as much for $\mathrm{Mg}$-Cu tapes as it is for $\mathrm{Al}-\mathrm{Cu}$ tapes, and the consolidated thickness is not correlated with the tape thickness in the $\mathrm{Mg}-\mathrm{Cu}$ tapes $\left(\mathrm{R}^{2}=0.06\right.$ and not shown for brevity). The absence of correlation suggests an additional source of variation, which is explored in the next paragraph.

The calculated shrinkage during hot pressing of each $\mathrm{Mg}-\mathrm{Cu}$ tape is shown in Fig. 3(b). The consolidation shrinkages for $\mathrm{Mg}-\mathrm{Cu}$ tapes are generally greater than for $\mathrm{Al}-\mathrm{Cu}$ tapes. Several factors (e.g., powder characteristics, additives) can cause differences in the powder packing density that result in different consolidation behaviors. ${ }^{40}$ Without establishing individual contributions, there is a reasonably tight linear correlation $\left(R^{2}=0.82\right)$ between the volume of polymers in $\mathrm{Mg}$ - $\mathrm{Cu}$ tapes and the consolidation shrinkage [Fig. 3(c)]. This suggests that the slurry formulation used to produce the tapes is a root cause for differences in the powder packing density and thus consolidation shrinkage. The correlation can also be used to predict the consolidated layer thickness of the $\mathrm{Mg}$-Cu tapes to within $\pm 9 \%$ from the tape formulation and tape thickness measurements. It was not necessary to consider the effect of the polymers for $\mathrm{Al}-\mathrm{Cu}$ tapes because there was better control over the binder formulation (polymer fraction within \pm 5 vol. \% for all $\mathrm{Al}-\mathrm{Cu}$ tapes compared to \pm 9 vol. \% for $\mathrm{Mg}-\mathrm{Cu}$ tapes). The thickness data are summarized in Table I. Consolidated thickness predictions based on the initial tape thickness and polymer content can now be made with $\pm 9 \%$ uncertainty for both tape systems at the current level of process control. The results suggest that better control over slurry formulations and tape casting thickness will reduce this aspect of uncertainty.

Density after hot pressing is the second metric for characterizing the tapes. The measured densities and relative densities of the composites are shown in Fig. 4. The theoretical densities of composites were determined by a rule of mixtures:

$$
\rho_{t h}=\sum_{i} f_{i} \rho_{t h, i}
$$

where $\rho_{t h}$ is the theoretical density of the composite, $f_{i}$ is the volume fraction of phase $i$, and $\rho_{t h, i}$ is the theoretical density of phase $i$ (e.g., $\mathrm{Al}, \mathrm{Cu}, \mathrm{Mg}$ ). Theoretical densities of composites were used to determine relative densities from measured densities. The

TABLE I. Summary of thickness data and observed limits compared to predictions.

\begin{tabular}{|c|c|c|c|c|}
\hline \multirow[b]{2}{*}{ Metric } & \multicolumn{3}{|c|}{ Consolidated } & \multirow{2}{*}{$\begin{array}{c}\text { Consolidated } \\
\text { Mg-Cu } \\
\text { Tapes }\end{array}$} \\
\hline & $\begin{array}{l}\text { Al-Cu } \\
\text { Tapes }\end{array}$ & $\begin{array}{c}\text { Al-Cu } \\
\text { Tapes }\end{array}$ & $\begin{array}{c}\mathrm{Mg}-\mathrm{Cu} \\
\text { Tapes }\end{array}$ & \\
\hline Mean thickness $(\mu \mathrm{m})$ & 81 & 48 & 85 & 34 \\
\hline Observed range $(\mu \mathrm{m})$ & \pm 9 & \pm 8 & \pm 15 & \pm 16 \\
\hline Mean shrinkage (\%) & NA & 41 & NA & 60 \\
\hline Observed limits (\%) & NA & \pm 9 & $\mathrm{NA}$ & \pm 9 \\
\hline
\end{tabular}

relative densities are measured densities expressed as a percent of theoretical density. The $\rho_{t h, i}$ values for $\mathrm{Al}, \mathrm{Cu}$, and $\mathrm{Mg}$ phases used in calculations were $2.70,8.93$, and $1.867 \mathrm{~g} / \mathrm{cm}^{3}$, respectively. ${ }^{49}$ The $\rho_{t h, i}$ value used for $\mathrm{Mg}$ is intentionally higher than the theoretical
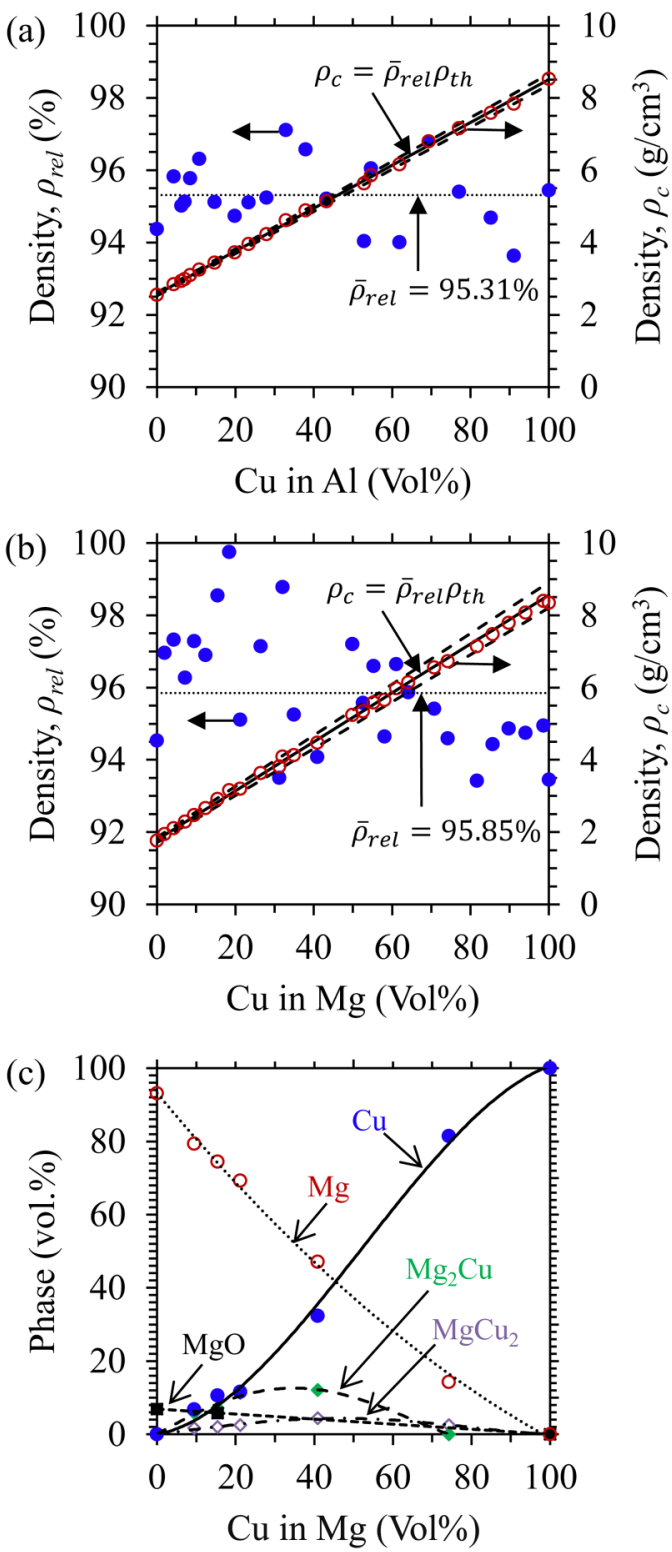

FIG. 4. Composite density $\left(\rho_{c}\right)$ and density relative to theoretical $\left(\rho_{\text {rel }}\right)$ for (a) $\mathrm{Al}-\mathrm{Cu}$ composites and (b) Mg-Cu composites. Mean density relative to theoretical (dotted line), predicted composite density based on the mean relative density (solid line), and observed density limits (dashed lines) are superimposed onto the plots. Density can be predicted to be within $\pm 2 \%$ of observed values for Al-Cu composites and $\pm 4 \%$ for $\mathrm{Mg}$-Cu composites using a rule of mixtures. (c) Phase estimates from X-ray diffraction data were used to correct theoretical and relative densities of $\mathrm{Mg}$-Cu composites in part (b); fits are superimposed onto the plot to guide the eye (n.b., no secondary phases were observed in the Al-Cu system). 
density of $\mathrm{Mg}\left(1.74 \mathrm{~g} / \mathrm{cm}^{3}\right)$ to account for significant $\mathrm{MgO}$ contamination with $3.58 \mathrm{~g} / \mathrm{cm}^{3}$ theoretical density. ${ }^{49}$ The $\mathrm{MgO}$ in $\mathrm{Mg}$ determined by XRD measurements was $13.23 \pm 0.12 \mathrm{wt}$. \% based on a $95 \%$ confidence interval, or $6.92 \pm 0.07 \mathrm{vol} \%$ using theoretical densities. Thus, Eq. (1) predicts a density of $1.867 \pm 0.001 \mathrm{~g} / \mathrm{cm}^{3}$ for the $\mathrm{Mg}-\mathrm{MgO}$ composite, which is used in place of the pure $\mathrm{Mg}$ density. Although $\mathrm{Mg}_{2} \mathrm{Cu}$ and $\mathrm{MgCu}_{2}$ intermetallic phases were observed, such intermetallic phases are insignificant to the density because the compound densities are very close to the weighted density of the pure metals with the same atomic proportions. No additional phases were found in the $\mathrm{Al}-\mathrm{Cu}$ system.

The measured and relative densities of $\mathrm{Al}-\mathrm{Cu}$ composites are shown in Fig. 4(a). The mean relative density of the Al-Cu composites is $95.31 \% \pm 0.01 \%$ of theoretical density based on a $95 \%$ confidence interval and the observed relative density range is within $\pm 1.79 \%$ of the mean. The relative density variation appears normally distributed around the mean value. The measured and relative densities of $\mathrm{Mg}$-Cu composites are shown in Fig. 4(b). The mean relative density of the $\mathrm{Mg}-\mathrm{Cu}$ composites is $95.85 \% \pm 0.02 \%$ based on a $95 \%$ confidence interval and the observed relative density range is within $\pm 3.89 \%$ of the mean. There is more variation in the relative density for the $\mathrm{Mg}$ - $\mathrm{Cu}$ composites compared to that for the $\mathrm{Al}-\mathrm{Cu}$ composites. Unlike the $\mathrm{Al}-\mathrm{Cu}$ system, there is a systematic variation in the relative densities with composition in the $\mathrm{Mg}-\mathrm{Cu}$ system. The relative density is biased toward lower values with increasing copper, as observed in prior studies. ${ }^{31,32}$ This is an important point because uncertainties in mean density values propagate to uncertainty in using and modeling $\mathrm{Mg}-\mathrm{Cu}$ GDIs. The volume fractions of the additional phases calculated from XRD measurements of the weight fractions are given in Fig. 4(c) for reference.

The compact density, $\rho_{c}$, can be estimated from the mean relative density, $\rho_{\text {rel }}$, and the theoretical density:

$$
\rho_{c}=\bar{\rho}_{r e l} \rho_{t h} .
$$

All measured density data for Al-Cu composites are within $\pm 2 \%$ of values predicted using Eq. (2), whereas measured density data for $\mathrm{Mg}-\mathrm{Cu}$ composites vary from the predictions by about twice as much, $\pm 4 \%$. The higher uncertainty for $\mathrm{Mg}$ - $\mathrm{Cu}$ composites is most likely due to the relative density bias discussed previously. Copper cannot be directly implicated for the bias toward lower density with increasing copper because the bias is not observed in the Al-Cu system. Factors like initial powder packing density and reactions can influence densification. ${ }^{40}$ A lower powder packing density due to a higher volume of polymers in the tape formulation [see Fig. 3] can contribute to the bias. Alternatively, reactions forming the additional phases [see Fig. 4(c)] can contribute to the enhanced densification in the Mg-rich compositions. The formation of secondary phases involves temperature-dependent reaction kinetics and so hot pressing thermal parameters (e.g., heating/cooling rates, hold temperatures, hold times) are root causes that can impact the quantities of additional phases and contribute to additional uncertainty for the $\mathrm{Mg}-\mathrm{Cu}$ system. Better control over the slurry formulations and the hot pressing parameters could reduce this aspect of modeling uncertainty. A summary of the density data is provided in Table II.
TABLE II. Summary of composite densities and observed limits compared to predictions.

\begin{tabular}{lcc}
\hline \hline & $\mathrm{Al}-\mathrm{Cu}$ & $\mathrm{Mg}-\mathrm{Cu}$ \\
Metric & Composites & Composites \\
\hline Mean relative density (\%) & 95.31 & 95.85 \\
Observed limits (\%) & \pm 2 & \pm 4 \\
\hline \hline
\end{tabular}

The third metric is acoustic velocity through the hot pressed compacts. A model of longitudinal acoustic velocity based on the Reuss approximation of aggregate elastic moduli has been described in detail and works quite well despite being considered a lower limit. ${ }^{31,32}$ The Reuss model assumption of stress continuity among phases appears to describe the aggregate elastic behavior of GDIs more closely than the alternative Voigt model assumption of equal strain in both phases. The model for acoustic velocity of a twophase composite is given by

$$
E=\rho v^{2}
$$

and

$$
E_{12}=\frac{E_{1} E_{2}}{\left(E_{1} f_{2}+E_{2} f_{1}\right)},
$$

where $E$ is the elastic modulus, $\rho$ is the density, $v$ is the acoustic velocity, $E_{12}$ is the elastic modulus of a two-phase composite made from phase 1 and phase $2, E_{1}$ is the elastic modulus of phase $1, E_{2}$ is the elastic modulus of phase $2, f_{1}$ is the volume fraction of phase 1 , and $f_{2}$ is the volume fraction of phase 2. $E_{1}$ and $E_{2}$ are usually determined from Eq. (3) with density and acoustic velocity data on the pure phases, prepared under suitable processing conditions. Then, $E_{12}$ is estimated from Eq. (4) and, with the measured density of the two-phase composite, Eq. (3) yields a model prediction for the acoustic velocity of the two-phase composite, $v_{12}$. We will make a slight modification to this approach to account for process variation by replacing measured density and acoustic velocity values of phase 1 and phase 2 with values that correspond to the mean relative density. Approximating acoustic velocity at the mean relative density requires elaboration.

Relative density is lower than theoretical because of porosity. Accounting for the effect of porosity on the model is not straightforward because there is no universal equation relating porosity to elastic modulus; neither stress nor strain compatibility between the matrix and the voids applies, and the aggregate properties depend on pore morphology and spatial distribution in addition to volume fraction. MacKenzie ${ }^{41}$ derived an equation to estimate the elastic modulus of a solid with a given radii distribution of spherical pores. Other studies have confirmed a complex dependence on pore morphology parameters that may be unknown ${ }^{42-45}$ and on a residual stress state, which can affect acoustic velocity by up to 30\%. ${ }^{46,47}$ MacKenzie $^{41}$ noted that an empirical approach incorporating experimentally determined values enables reliable estimates of porosity corrections in the presence of such combined effects. 
The dependence of acoustic velocity on porosity can be described generically as

$$
v(P)=v_{o} \times F(P),
$$

where $v(P)$ is the acoustic velocity as a function of porosity, $v_{o}$ is the acoustic velocity without porosity, and $F(P)$ is a porosity function that corrects the acoustic velocities to the appropriate mean relative density, $1-P_{\text {avg }}$, where $P_{\text {avg }}$ is the mean pore fraction. $F(P)$ is calibrated at the measured porosity level, $P_{\exp }$ (e.g., $1-\rho_{\text {rel }}$ ),

$$
v_{o}=\frac{v\left(P_{\exp }\right)}{F\left(P_{\exp }\right)},
$$

and substituting $v_{o}$ from Eq. (6) into Eq. (5) gives the following expression:

$$
v\left(P_{\text {avg }}\right)=v\left(P_{\text {exp }}\right) \times \frac{F\left(P_{\text {avg }}\right)}{F\left(P_{\text {exp }}\right)} .
$$

Equation (7) yields the acoustic velocity of the two phases at the mean relative density once the experimental and mean relative densities of the two phases are known. Equations (5) and (7) are written generically so that any porosity function can be applied. In the absence of a universal porous elasticity model, the porosity function used here is derived from Kingery's simplification ${ }^{48}$ of MacKenzie's derivation and the following expression for density:

$$
E(P)=E_{o}\left(1-1.9 P+0.9 P^{2}\right),
$$

and

$$
\rho(P)=\rho_{t h}(1-P),
$$

where $E(P)$ is the elastic modulus as a function of pore fraction, $E_{o}$ is the elastic modulus without porosity, and $\rho(P)$ is the density as a function of pore fraction. Using Eqs. (8) and (9) to derive the acoustic velocity model from Eqs. (3) and (4) and comparing to Eq. (5) results in the following porosity function:

$$
F(P)=\left(\frac{1-1.9 P+0.9 P^{2}}{1-P}\right)^{\frac{1}{2}} .
$$

Table III shows the data and results of the application of these equations to obtain the mean density and mean acoustic velocity of phase $1(\mathrm{Mg}$ or $\mathrm{Al})$ and phase $2(\mathrm{Cu})$, to be used as the Reuss-derived model inputs for acoustic velocity of the composites [see Eqs. (3) and (4)].

The measured and predicted acoustic velocities of $\mathrm{Al}-\mathrm{Cu}$ composites are shown in Fig. 5(a); values agree within $\pm 3 \%$. Corresponding values of $\mathrm{Mg}-\mathrm{Cu}$ composites [Fig. 5(b)] agree within $\pm 4 \%$. Like the density predictions from which the acoustic velocity model is derived, acoustic velocity prediction errors for $\mathrm{Mg}$-Cu composites are higher than for $\mathrm{Al}-\mathrm{Cu}$ composites, most likely because of the same root causes. Thus, better control over the slurry formulations and hot pressing parameters is likely to reduce
TABLE III. Measured and mean densities, porosity fractions, and acoustic velocities used to predict acoustic velocities of composites.

\begin{tabular}{lcccccc}
\hline \hline System & Phase & Data & $\rho_{\text {rel }}(\%)$ & $P$ & $\begin{array}{c}\rho \\
\left(\mathrm{g} / \mathrm{cm}^{3}\right)\end{array}$ & $\begin{array}{c}v \\
(\mathrm{~km} / \mathrm{s})\end{array}$ \\
\hline $\mathrm{Al}-\mathrm{Cu}$ & $\mathrm{Al}$ & Measured & 94.37 & 0.0563 & 2.55 & 5.83 \\
& & Mean & 95.31 & 0.0469 & 2.57 & 5.85 \\
& $\mathrm{Cu}$ & Measured & 95.44 & 0.0456 & 8.52 & 3.87 \\
& & Mean & 95.31 & 0.0469 & 8.51 & 3.86 \\
$\mathrm{Mg}-\mathrm{Cu}$ & $\mathrm{Mg}$ & Measured & 94.53 & 0.0547 & 1.77 & 5.41 \\
& & Mean & 95.85 & 0.0415 & 1.79 & 5.44 \\
& $\mathrm{Cu}$ & Measured & 93.45 & 0.0655 & 8.35 & 4.13 \\
& & Mean & 95.85 & 0.0415 & 8.56 & 4.17 \\
\hline \hline
\end{tabular}

acoustic velocity prediction uncertainty. A summary of the observed acoustic velocity prediction limits is given in Table IV.

The purpose of characterizing density and acoustic velocity is to calculate acoustic impedance. The acoustic impedance, $z$,
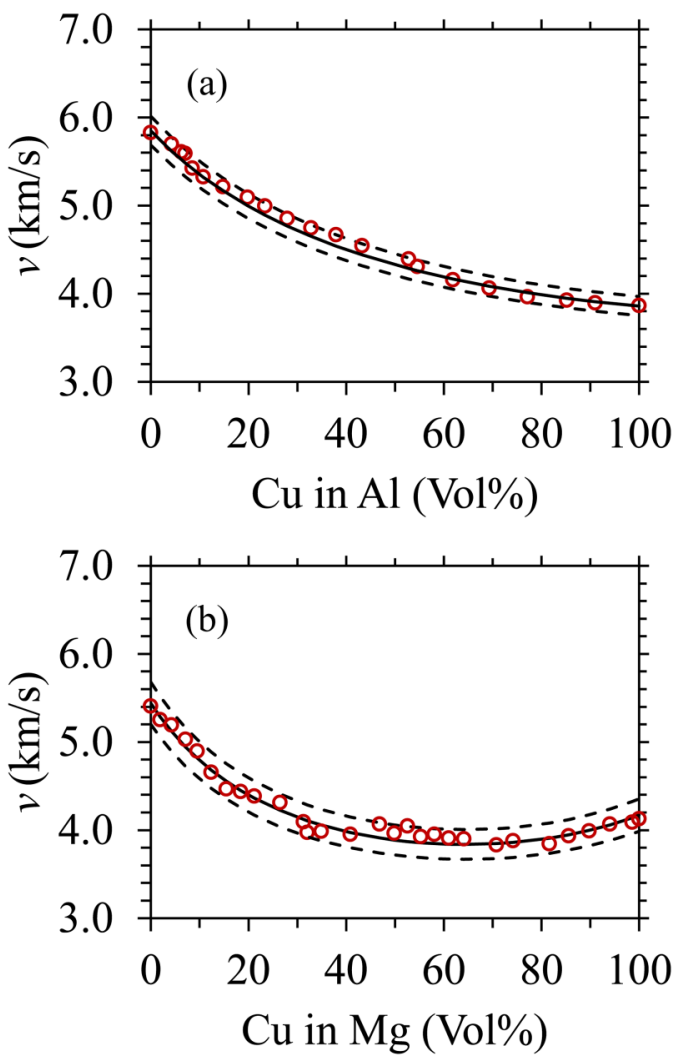

FIG. 5. Longitudinal acoustic velocities through (a) Al-Cu composites and (b) $\mathrm{Mg}$-Cu composites. Acoustic velocity predictions (solid lines) can be made to within $\pm 3 \%$ of experimental observations (open circles) and within $\pm 4 \%$ for $\mathrm{Mg}-\mathrm{Cu}$ composites using a Reuss-bound model (observed limits from predictions are given as dashed lines). 
TABLE IV. Observed limits for acoustic velocity compared to predictions.

\begin{tabular}{lc}
\hline \hline System & Observed limits (\%) \\
\hline $\mathrm{Al}-\mathrm{Cu}$ & 3 \\
$\mathrm{Mg}-\mathrm{Cu}$ & 4 \\
\hline \hline
\end{tabular}

is given by ${ }^{31-33}$

$$
z=\rho v
$$

Acoustic impedance predictions can be made using density predictions [Eq. (2)] and acoustic velocity predictions [Eq. (7)] as inputs to Eq. (11). Impedance values calculated from experimental data and from this prediction scheme are shown in Fig. 6; impedance predictions are accurate to $\pm 4 \%$ for $\mathrm{Al}$ - $\mathrm{Cu}$ composites and $\pm 6 \%$ for $\mathrm{Mg}-\mathrm{Cu}$ composites. These observed limits are consistent with the propagation of the errors on density and acoustic velocity and so, again, better control over slurry formulations and hot pressing parameters should reduce acoustic impedance prediction uncertainty. All aspects of tape characterization are now complete. The second step of GDI qualification is process verification.

\section{B. GDI process verification}

Section III A focused on a comparison between the $\mathrm{Al}-\mathrm{Cu}$ and $\mathrm{Mg}-\mathrm{Cu}$ systems because we are substituting $\mathrm{Al}$ for $\mathrm{Mg}$ in previously developed $\mathrm{Mg}-\mathrm{Cu}-\mathrm{W}$ GDIs. ${ }^{33}$ We applied a similar analysis to the $\mathrm{Cu}-\mathrm{W}$ system to establish uncertainties, which is only summarized here for brevity (Table V). The uncertainty in predicting thickness, density, and acoustic velocity was $12 \%, 1 \%$, and $1 \%$, respectively. There is greater uncertainty in thickness arising from the tape casting process and lesser uncertainty in density and acoustic velocity arising from both tape casting and thermal processing compared to those in the $\mathrm{Al}-\mathrm{Cu}$ and $\mathrm{Mg}-\mathrm{Cu}$ composites. However, these limits were inferred from a more limited data set (only 8 composite samples compared to at least 20 in each of the $\mathrm{Al}-\mathrm{Cu}$ and $\mathrm{Mg}-\mathrm{Cu}$ systems).

The prediction methods that have been developed in this work can be used to model the acoustic impedance profile of any GDI tape-stacking sequence, which is typically done via a lengthy process (months of effort) that determines the thickness and acoustic impedance of each individual layer. ${ }^{31-33,50}$ The predicted impedance profile (with calculated uncertainty) of a 52-layer $\mathrm{Al}-\mathrm{Cu}-\mathrm{W}$ GDI are compared to data from the traditional experimental tape characterization process in Fig. 7. The limits shown are extreme limits for GDI-to-GDI impedance profile variation (e.g., the upper limit assumes that each consolidated layer has the minimum predicted thickness and the maximum predicted impedance). The modeled and measured impedance profiles agree to within $\pm 4 \%$. This agreement represents a major progress in the practical application of new GDI designs, reducing the time for the first stage of GDI qualification from months to weeks since only tape thicknesses and full characterization of the pure phases are required (as opposed to full characterization of each individual compositional layer), which reduces the number of tapes to characterize by $90 \%$.
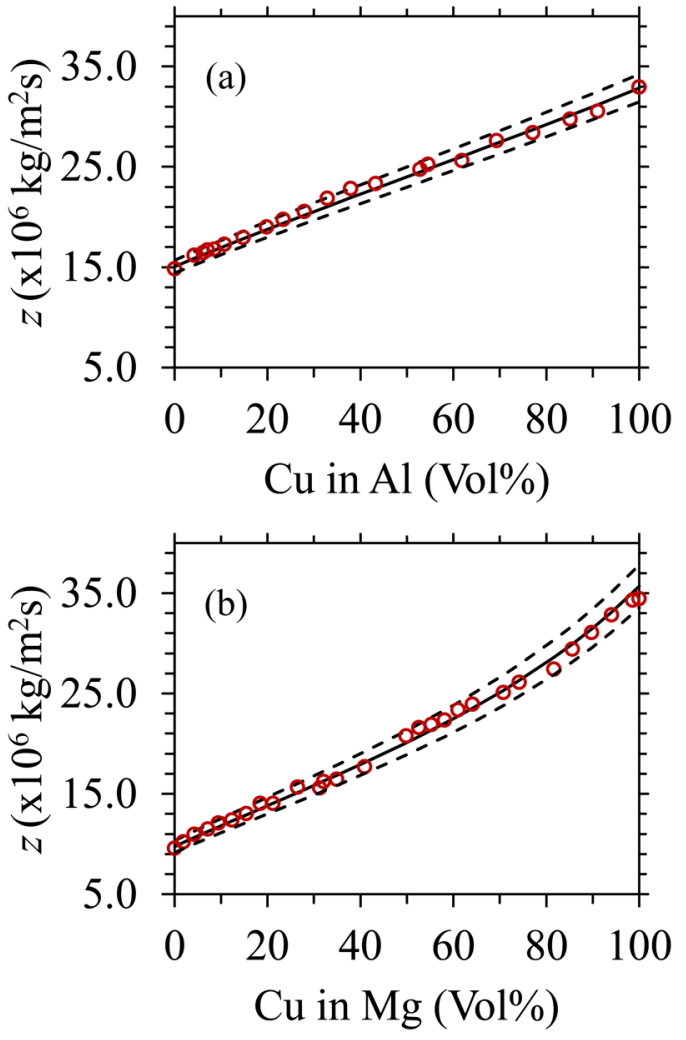

FIG. 6. Acoustic impedance of (a) Al-Cu composites and (b) Mg-Cu composites. Acoustic impedance predictions (solid lines) can be made to within $\pm 4 \%$ of experimental observations (open circles) for Al-Cu composites and within $\pm 6 \%$ for Mg-Cu composites using the density and acoustic velocity models (observed limits from predictions are given as dashed lines).

The predicted thickness of a GDI having the impedance profile depicted in Fig. 7 is $2.40 \pm 0.23 \mathrm{~mm}$. This corresponds to an estimated $10 \%$ uncertainty in the length or rate of the compression ramp that will result from the use of the GDI in a dynamic compression experiment. ${ }^{30}$ This level of uncertainty is comparable to the reported current input accuracy of Sandia's $\mathrm{Z}$ machine. ${ }^{51}$ Although the input wave may therefore vary from one GDI to another, the thickness of each GDI is known before it is used in a given experiment and the input wave (i.e., drive) for each experiment is directly measured. Hence, the selection of a subset of

TABLE V. Observed limits compared to predictions for thickness, density, acoustic velocity, and acoustic impedance for Cu-W composites.

\begin{tabular}{lc}
\hline \hline Parameter & Observed limits (\%) \\
\hline Thickness & 12 \\
Density & 1 \\
Acoustic velocity & 1 \\
Acoustic impedance & 2 \\
\hline
\end{tabular}




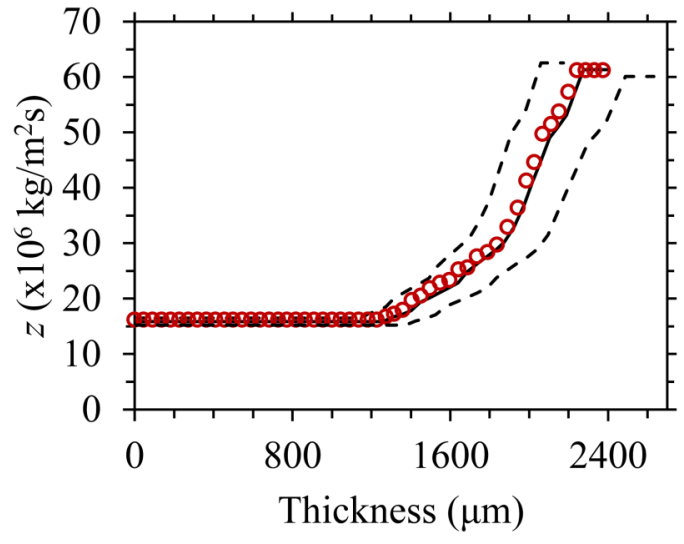

FIG. 7. Impedance profile of an Al-Cu-W GDI as a function of thickness determined by predictions and experimental validation (open circles). The predicted impedance profile is given as a solid line and limits derived from thickness and impedance prediction limits are given as dashed lines. The predicted GDI thickness based on the specific tape-stacking sequence is $2.40 \pm 0.23 \mathrm{~mm}$ when considering the prediction limits, which agrees well with the observed thicknesses of 13 of these GDls (the mean thickness of $13 \mathrm{GDls}$ is $2.42 \pm 0.06$ based on a $95 \%$ confidence interval and ranged from 2.21 to $2.59 \mathrm{~mm}$ ).

finished GDIs with a narrower thickness range allows a series of experiments with nearly identical compression ramps.

We have fabricated 13 GDIs with the nominal impedance profile demonstrated in Fig. 7 to demonstrate the benefit of GDI selection criteria. The mean thickness of the 13 GDIs is $2.42 \pm 0.06$ $\mathrm{mm}$ (95\% confidence interval) and ranged from 2.21 to $2.59 \mathrm{~mm}$. The measured range is in excellent agreement with the predicted limits $(2.40 \pm 0.23 \mathrm{~mm})$. Selecting a subset of 5 GDIs from the original 13 yields a thickness range from 2.42 to $2.45 \mathrm{~mm}$ and reduces variations in pressure ramp uncertainty to $1 \%$.

We so far focused on GDI-to-GDI variation, but the uniformity of a given GDI is also important for dynamic compression experiments. Each fabricated GDI is a cylinder with $31.75 \mathrm{~mm}$ diameter and the microstructure should be as uniform as possible over the entire area of the GDI to allow flexible placement of measurement probes. Next, we explore the microstructure and composition gradient on a full-depth, full-radius cross section of a GDI, profilometry to check surface height variation, and ultrasonic testing to confirm uniformity.

Figure 8 shows a representative microstructure cross section of an $\mathrm{Al}-\mathrm{Cu}-\mathrm{W}$ GDI. It is difficult to decipher the original tape layer boundaries, demonstrating a smooth compositional gradient. Overall, the $\mathrm{Al}-\mathrm{Cu}-\mathrm{W}$ GDI appears to have good microstructure uniformity. There are rare instances of abnormally large $\mathrm{Al}$ grains in the microstructure, which could be eliminated by better control of the Al particle size distribution.

Height images of two Al-Cu-W GDIs are shown in Fig. 9. The white arrow across the height image in Fig. 9(a) depicts the direction of maximum side-to-side thickness variation across the surface, which causes the maximum convex bow height (closed circle) to shift from the center (open circle). The mean side-to-side

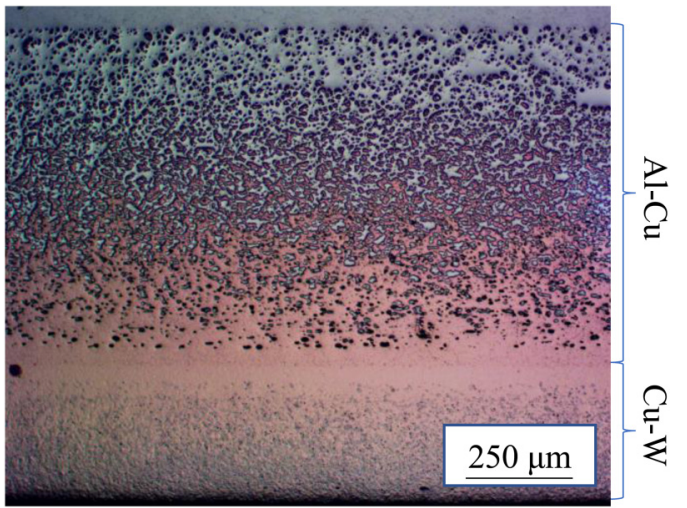

FIG. 8. Optical micrograph of the graded section of an Al-Cu-W GDI, which demonstrates the transformation of a series of discrete compositional layers into a smoothly graded structure as well as good microstructure uniformity.

thickness variation from measurements on seven GDIs was $20 \pm 10$ $\mu \mathrm{m}$ (95\% confidence interval) and ranged from 0 to $40 \mu \mathrm{m}$. The mean bowing height from measurements on seven GDIs was $30 \pm$ $10 \mu \mathrm{m}$ (95\% confidence interval) and ranged from 20 to $40 \mu \mathrm{m}$. The extent of bowing and side-to-side thickness variation is comparable to previously developed GDIs. ${ }^{32,33}$ Bowing and side-to-side thickness variation cause local compression or dilation of the impedance profile at different points on the impacting surface that can contribute to PDV measurement variation.

The extent of side-to-side thickness variation or bowing $(\leq 40 \mu \mathrm{m})$ compared to the thickness of the GDI $(\geq 2.17 \mathrm{~mm})$ suggests that these factors may contribute up to about $1.8 \%$ to PDV measurement uncertainty at different probe locations. However, this may be an overly conservative limit because the effects of bowing and side-to-side thickness variation can be partially mitigated by strategic selection of probe locations. For example, Fig. 9(b) demonstrates a GDI that is bowed, but without a significant side-to-side thickness variation. For this GDI, probes located at the same radial distance from the center (e.g., at the positions of the arrows along the dotted curve) would be minimally affected by GDI side-to-side thickness variation and bowing due to symmetry.

Nondestructive evaluation of each GDI with ultrasonic testing is performed before it is considered for use in a dynamic compression experiment. ${ }^{32,33}$ Such an evaluation is demonstrated by the A-, B-, and C-scans in Fig. 10. An A-scan records the amplitude of echoes returned to the transducer as a function of time; the frontside and backside reflections can be picked and yield a transit time through the GDI. This can be compared to a prediction from the tape characterization data. The waveform of an Al-Cu-W GDI is depicted in Fig. 10(a). The time between the peak amplitudes of the reflections from the front $\mathrm{Al}$ surface and the back $\mathrm{Cu} / \mathrm{W}$ surface is $0.90 \mu \mathrm{s}$. This precisely matches the acoustic time-of-flight expected from thickness and acoustic velocity data $(0.90 \mu$ s for the $2.36 \mathrm{~mm}$ thickness of this GDI).

A B-scan is given in Fig. 10(b), which represents the waveform (A-scan) as a function of position as the transducer is scanned 

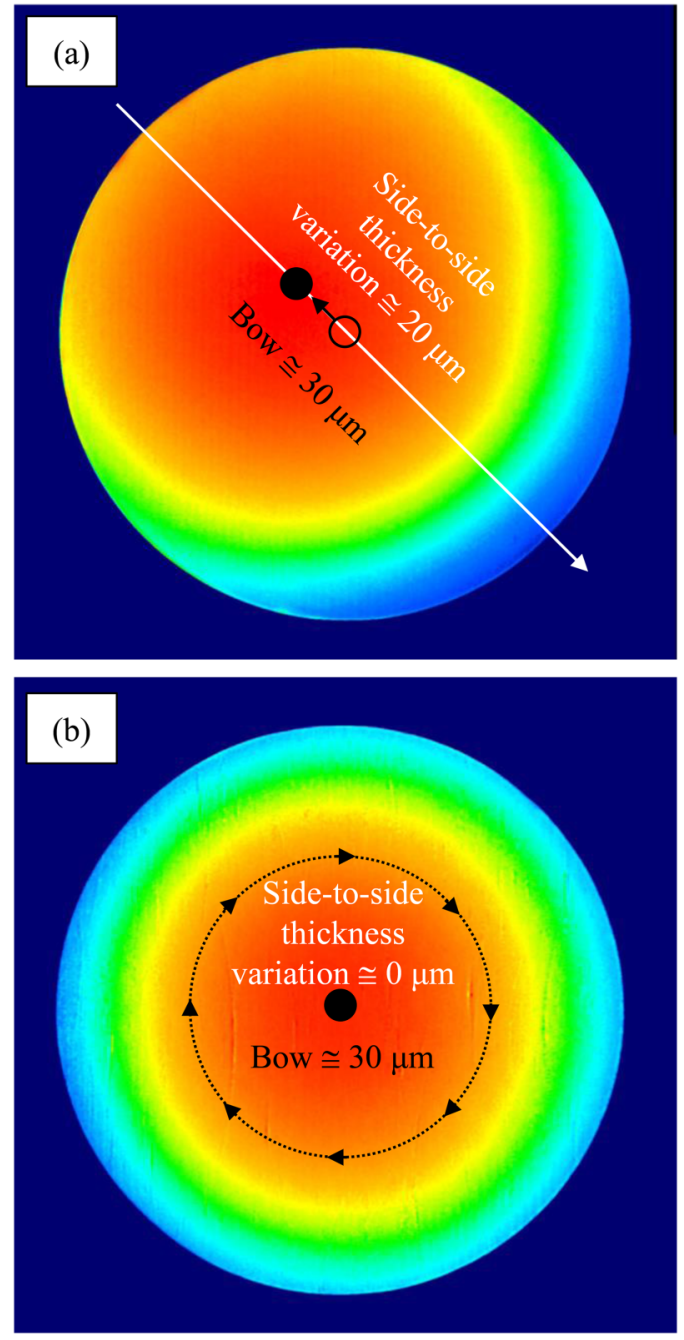

FIG. 9. (a) Height image of the back surface of an Al-Cu-W GDI with a 31.75 $\mathrm{mm}$ diameter, a side-to-side thickness variation of about $20 \mu \mathrm{m}$, and a bow height of about $30 \mu \mathrm{m}$ [the white arrow depicts the direction of maximum side-to-side thickness variation, which causes the maximum convex bow height (closed circle) to shift from the center (open circle)]. (b) A height image of a GDI without a side-to-side thickness variation, but with a similar bow height, shows that strategically placed probes at a constant radial distance from the center could exploit the symmetry of this GDI to minimize geometric trace-to-trace differences in PDV profiles.

along a line, in this case a $31.75 \mathrm{~mm}$ grand diameter of the GDI. The color scale in the B-scan represents the echo amplitudes returned to the transducer as a function of time (the waveform from an A-scan is drawn in the center of the B-scan to help clarify this visualization). The uniformity of the color bands over the inner $29 \mathrm{~mm}$ of the scan length shows that the waveform is uniform across the scan length except where there are edge effects (i.e., about 1-2 $\mathrm{mm}$ from each edge). There are no major reflections between the signals from the front and back surfaces anywhere along the scan length, and both the position and the intensity of the reflections are uniform. The parallel dotted lines drawn in Fig. 10(b) show that deviations from surface parallelism are too small to be observed by this method.

A C-scan represents the spatial uniformity over the entire GDI surface, typically by plotting either the acoustic time-of-flight or the amplitude of the largest reflection in a specified time frame as a function of scan position. For example, the C-scan in Fig. 10(c) depicts the amplitude of the back $\mathrm{Cu}-\mathrm{W}$ surface reflection from the GDI across the scan area. Any abnormalities in the GDI that cause excessive acoustic scattering or reflection would decrease the amplitude of the back surface reflection. However, the amplitude of the back surface reflection is about $57 \% \pm 1 \%$ over the entire surface and demonstrates excellent radial uniformity of the GDI.

\section{GDI deployment}

Experimental diagnostics have rarely been used to explore the uniformity of a dynamic compression response in the radial direction because such measurements are easily affected by lateral release waves. ${ }^{3}$ Here, we carefully designed an experiment to evaluate radial uniformity using a large-diameter, thin target that keeps lateral release waves away from the probed region. The results can be used to evaluate the intrinsic uniformity of the drive provided by the GDI. As noted above, the GDI used was typical of the selected group of most uniform GDIs, with $30 \mu \mathrm{m}$ bowing, $30 \mu \mathrm{m}$ side-to-side thickness variation, and $2.36 \mathrm{~mm}$ thickness, implying thickness variations of up to $1.3 \%$ of the total GDI thickness. The GDI diameter is turned down before mounting into the sabot; the diameter reduction of about $20 \%$ suggests up to $1.1 \%$ thickness variation across the final flyer plate.

The plot in Fig. 11 shows the apparent particle velocity traces from five PDV probes located at 2, 3, 4, 5, and $6 \mathrm{~mm}$ from the center of an Al-LiF target (see Fig. 1). All particle velocity traces show the shock breakout, followed by velocity stabilization at about $2500 \mathrm{~m} / \mathrm{s}$ for about $200 \mathrm{~ns}$ because of the constant impedance $\mathrm{Al}$ section at the front of the GDI. The particle velocity then rises to about $3600 \mathrm{~m} / \mathrm{s}$ over another $200 \mathrm{~ns}$. There is a minor release due to the slight separation between the Al-Cu-W GDI and the Ta backing, where there is a glue line, followed by a rise back to about $3700 \mathrm{~m} / \mathrm{s}$. The particle velocity stabilized to a plateau for about $300 \mathrm{~ns}$ due to the constant impedance of the Ta plate glued onto the back of the GDI, followed finally by target decompression. The release wave from the glue layer is acceptable if the goal of the experiment is achieved before the release occurs or if the release does not directly affect data of interest beyond the release. However, in some applications, the glue release could affect the thermodynamic path and path-dependent variables. In such cases, the release wave may be eliminated by diffusion bonding rather than gluing the constant impedance backing to the GDI (this method has been used in other GDIs, not shown here). Since the primary goal of this experiment is to test radial uniformity of the compression ramp, it was not necessary to eliminate this release wave from this shot.

Bastea et al. suggested that properly diagnosed PDV measurement variations can be minimized by time corrections to the 

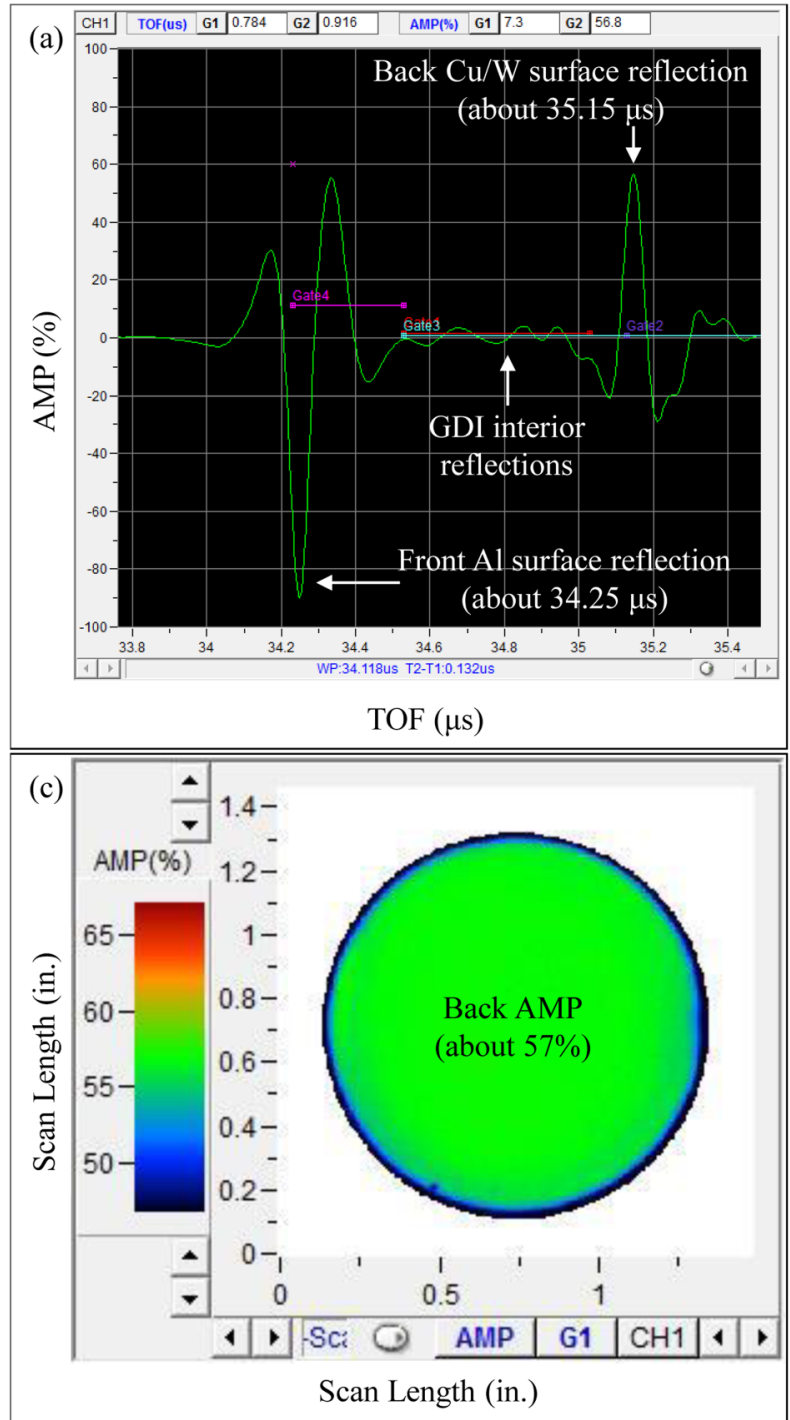

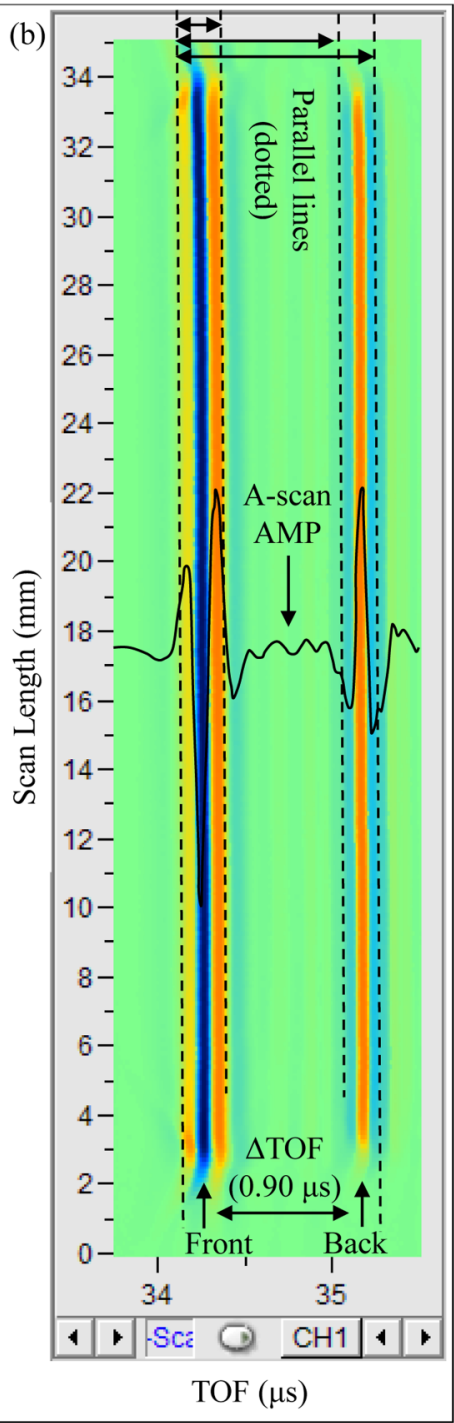

FIG. 10. Ultrasonic (a) A-scan, (b) B-scan, and (c) C-scan of an Al-Cu-W GDI. The A-scan waveform measures the acoustic time-of-flight between the front and back surface reflections $(0.90 \mu \mathrm{s})$, which is consistent with the expected transit time for the $2.36 \mathrm{~mm}$ thick GDI. The B-scan demonstrates that the waveform is consistent across a grand diameter of the GDI with no major internal reflections. The $\mathrm{C}$-scan plots the back surface reflected amplitude in two dimensions, showing no major internal scattering or reflections from defects. particle velocity traces. ${ }^{34}$ Time shifts between PDV traces might be due to GDI factors (nonuniform impedance, bowing, side-to-side thickness variation, and tilt between projectile and target surfaces due to sabot mounting or in-flight rotation), target factors (variations in thickness, nonplanarity), or diagnostic factors (cables carrying current to the recording oscilloscopes, etc.). Diagnostics are designed or calibrated to minimize the timing offset and the target thickness is usually controlled to be within $1 \mu \mathrm{m}$, so GDI and projectile factors are most likely responsible for timing offsets.

The maximum timing offset of the shock breakout between the different particle velocity traces is $65 \mathrm{~ns}$. This corresponds to a linear distance of $250 \mu \mathrm{m}$ based on the projectile velocity $(3.85 \mathrm{~km} / \mathrm{s})$. This distance is greater than the extent of side-to-side thickness variation or bowing within the GDI, which can account only for offsets of about $\pm 4 \mathrm{~ns}$ and indicates that tilt between the projectile and the target surfaces due to sabot mounting and/or in-flight rotation is most likely responsible for the timing offsets.

Figure 12(a) depicts results from an analysis of projectile tilt. Two of the probes yielded equal shock breakout times, each offset by $+10 \mathrm{~ns}$ from the average shock breakout time. We therefore developed a model for tilt of a planar projectile with a tilt rotation axis parallel to the line between these two probe locations. Assuming that the timing offsets are due to a simple tilt of a planar projectile only, we obtain the timing offset for each other point by projecting parallel timing offset contours through those points (red lines). Figure 12(b) shows that the measured timing offsets are linear when plotted against the distance between the offset contours in the assumed tilt direction. The strong correlation of the linear fit $\left(\mathrm{R}^{2}=0.998\right)$ suggests that indeed tilt is the primary cause for shock breakout timing differences. The slope of $5.37 \mathrm{~ns} / \mathrm{mm}$, for a 


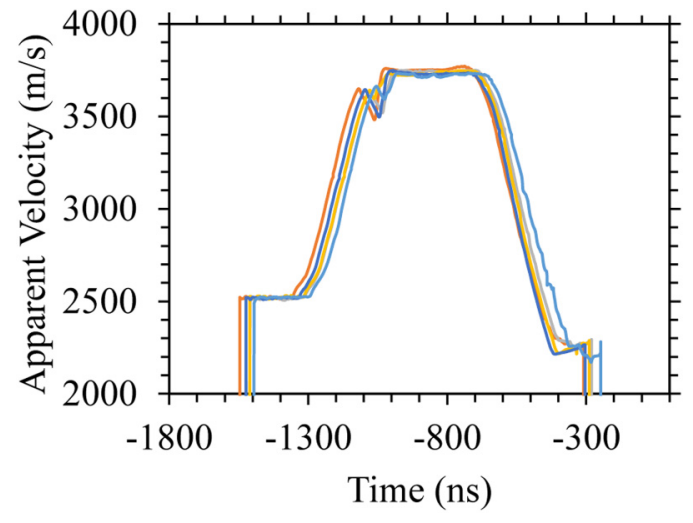

FIG. 11. Five uncorrected PDV traces from a dynamic compression experiment collected at 2-6 $\mathrm{mm}$ radial distances from the center of an Al-LiF bilayer target. The offsets among individual traces can be caused by GDI factors, target factors, or limitations of the PDV measurement system.

(a)
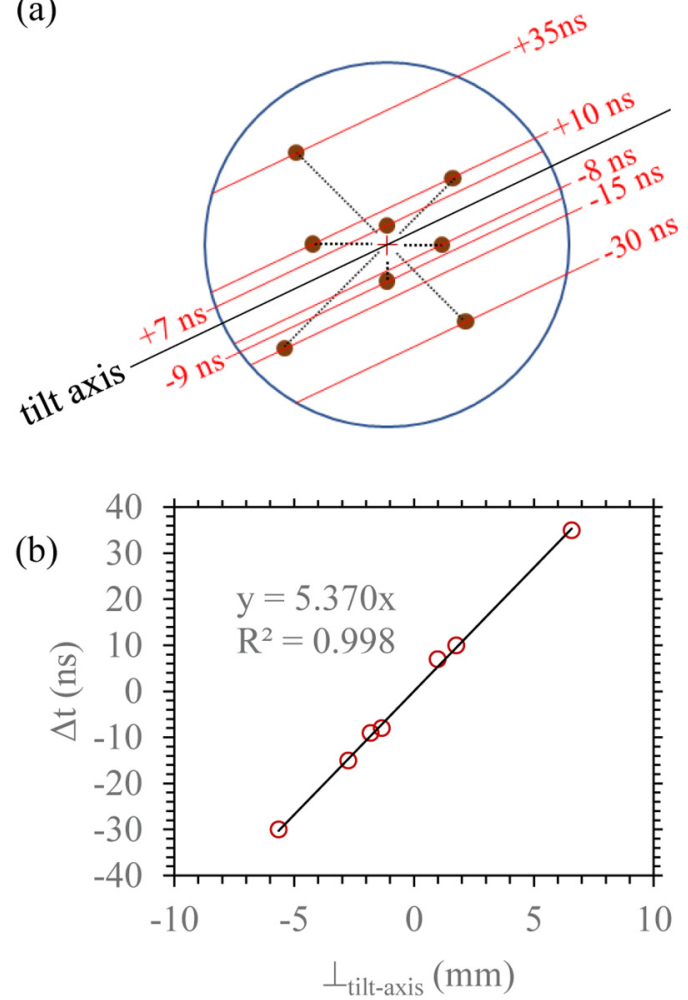

FIG. 12. (a) Depiction of an assumed tilt axis of rotation relative to PDV probe locations and the shock breakout timing offsets based on assumed contours and measurements. (b) The measured shock breakout timing offsets compared to the orthogonal distance between contours and linear fit used for offset calibrations. projectile velocity of $3.85 \mathrm{~km} / \mathrm{s}$, corresponds to $21 \mathrm{mrad}\left(1.2^{\circ}\right)$ of tilt between projectile and target surfaces; this is a reasonable value for the Caltech two-stage gas gun, which has about $0.5 \mathrm{~m}$ of free flight between the muzzle and the impact plane. A tilt calibration, using the correlation in Fig. 12(b), will be used to correct timing offsets between the different particle velocity traces. A constant translation factor will also be applied to all the traces in addition to the offset correction so that the average shock breakout time is moved to the shock breakout time determined by tilt-free 1D simulations (189 ns beyond impact time at $t=0 \mathrm{~ns}$ ). Window velocity corrections according to Rigg et al. will also be applied to the data. ${ }^{37}$

The five calibrated PDV traces are depicted in Fig. 13(a). The PDV traces are in excellent agreement up to the end of the compression ramp. There is still a considerable amount of variation afterward, most likely a result of nonuniform glue layer thickness as a result of side-to-side thickness variation and bowing affecting the mating between the GDI and Ta backing. Figure 13(b) presents the velocity variation from the mean velocity throughout the ramp compression experiment. The observed velocity variation of any

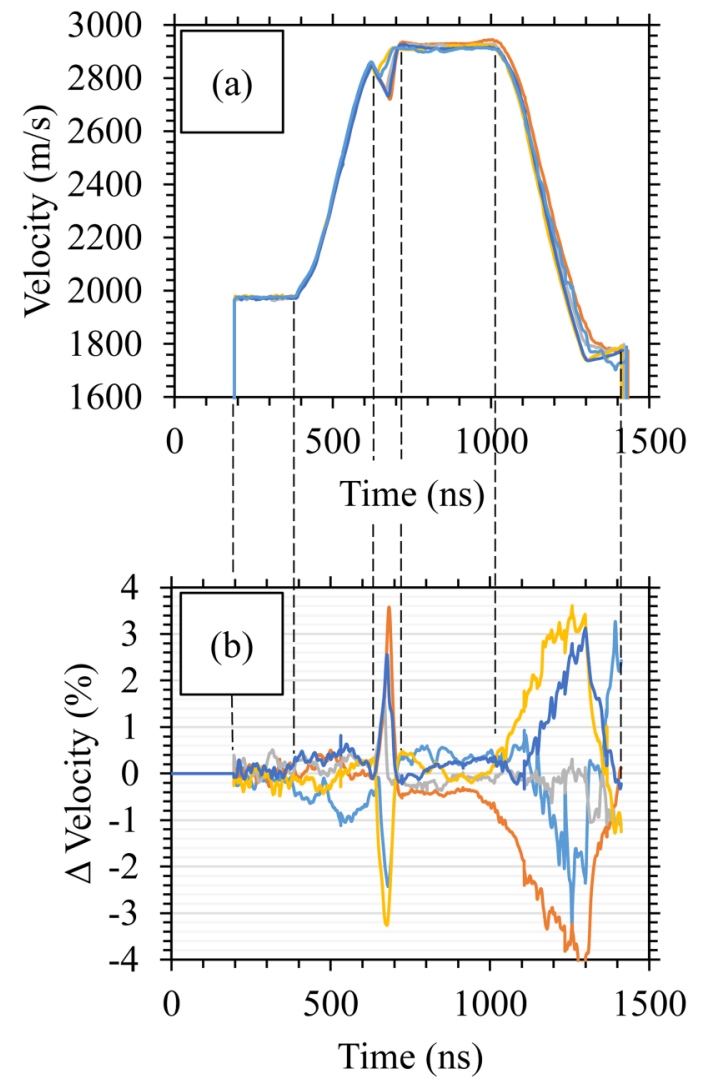

FIG. 13. (a) Five PDV traces from a dynamic compression experiment after time and velocity corrections (impact at $t=0 \mathrm{~ns}$ ) and (b) observed velocity variation of individual PDV traces relative to the mean. Variation in the initial velocity stabilization and ramp compression segments are within $\pm 1.1 \%$ and the root mean square of variation is $0.3 \%$. 
PDV trace is less than $\pm 1.1 \%$ from the mean trace during both the initial velocity stabilization period and the dynamic ramp compression interval with root mean square of these deviations of $0.3 \%$. This level of variation provides the best estimate of the PDV measurement error due to both GDI nonuniformity (e.g., side-to-side thickness variation and bowing) and the limits of PDV analysis. There are greater differences between the segments of the traces marking the glue layer release wave due to variations in glue layer thickness. Nevertheless, the variation about the mean is only $\pm 0.6 \%$ during the upper velocity stabilization period. Finally, there are larger differences in the decompression interval most likely attributed to offsets created by the variable glue line thickness.

Interestingly, $\pm 1.1 \%$ velocity variation about the mean PDV trace is entirely consistent with the expected range due to measured geometric bowing and side-to-side thickness variations relative to the mean thickness of the tested GDI. However, this agreement may be a fortuitous product of confounding errors. Factors related to the limits of PDV analysis may be contributing some portion of the variation among the five traces, although experience suggests that PDV uncertainty can be less than $0.1 \%$ in some experiments. Assigning causes to the observed variation would require additional experiments that replicate this result and use GDIs with different geometric nonuniformity parameters. Future development studies of this type would continue to improve the precision and reproducibility of ramp compression experiments.

Figure 14 shows an analysis of the shock ramp compression experiment compared to simulations. The plot shows the $95 \%$ confidence interval band of the mean and a $95 \%$ prediction interval band, both centered on the mean velocity measured with the five probes. Simulations that use experimental inputs from the tape characterization models are also shown, including the derived limits. The simulation and the experiment are in very good agreement.

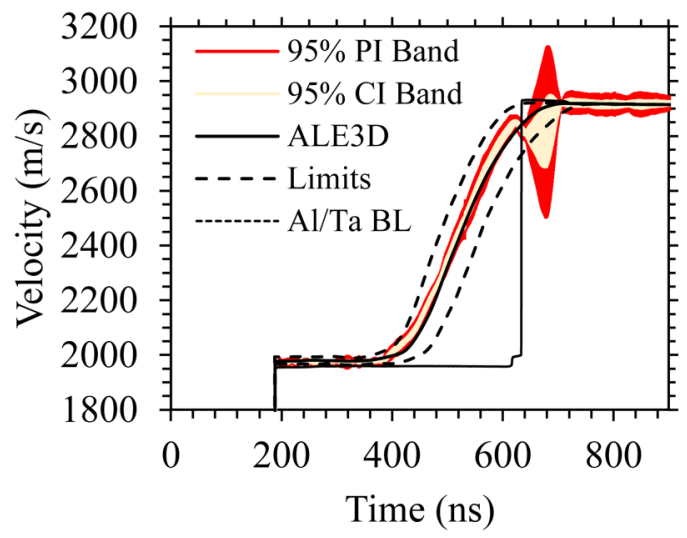

FIG. 14. A comparison between experimental PDV trace data and simulations are in excellent agreement. The $95 \%$ confidence interval $(\mathrm{Cl})$ band and the prediction interval (PI) band centered around the mean velocity were derived from the five experimental PDV traces, whereas the ALE3D trace is simulated. The ALE3D trace and limits are derived from the tape characterization models. A trace simulating a two-step shock from a bilayer $(\mathrm{BL})$ of metal standards (1100 $\mathrm{Al} / \mathrm{Ta}$ ) with $\mathrm{Al}$ thickness consistent with nominal thickness of the GDI is also included for comparison purposes.
The simulation closely follows the bottom of the $95 \%$ confidence interval band. The discrepancy, if any, is consistent with the slightly lower thickness of the experimental GDI $(2.36 \mathrm{~mm})$ compared to the model thickness $(2.40 \mathrm{~mm})$. The intervals generally fit well within the model limits. The model and limits were derived from a much smaller data set compared to the conventional qualification process, further demonstrating the ability to use predictive methods to expedite GDI qualification for dynamic ramp compression experiments through tape characterization, process verification, and deployment.

\section{CONCLUSIONS}

A new high-impedance Al-Cu-W-Ta GDI based on the tape casting and laminating methodology has been fabricated and compared to a previously developed $\mathrm{Mg}-\mathrm{Cu}-\mathrm{W}$ GDI. The use of tapes containing mixtures of metal particles allows fine adjustments to the GDI impedance profile. Continuing to develop the tape casting and laminating methods is of interest for experiments that require a prescribed pressure ramp. Replacing $\mathrm{Mg}$ with $\mathrm{Al}$ improves the strength of the impactor at high initial shock pressures because the Al FCC phase melts at a higher pressure than the Mg HCP phase. A Ta backing can extend the duration of the peak compression states to facilitate probing these states, which has implications for the discovery and synthesis of high-pressure phases.

Predictive methods have been developed to model the acoustic impedance profile of a GDI design and to quantify uncertainty limits. The predictive methods can reduce the tape characterization aspect of GDI qualification from months to weeks since only a subset of the data is required; data collection is reduced by $90 \%$. Reduced qualification time also facilitates repetition experiments to monitor, assign, and reduce root causes of variation leading to uncertainty, which will enable future reliability improvements. The primary root causes of variation currently identified through analysis of the uncertainty limits include variable slurry formulations and hot pressing parameters. Another benefit of $\mathrm{Al}-\mathrm{Cu}$ over $\mathrm{Mg}-\mathrm{Cu}$ was noted during characterization, namely, the absence of any detectable intermetallic compounds in the front section of the new Al-Cu-W-Ta GDI.

There is excellent agreement between the modeled impedance profile and the impedance profile measured by the traditional experimental verification procedure. The largest source of a priori uncertainty in impedance profile resulting from the GDI manufacturing process is total thickness variation, which might affect the ramp compression time by up to $10 \%$ if all GDIs in a manufacturing run are used indiscriminately. However, total thickness is easy to measure and hence GDI selection criteria can reduce this source of error to $1 \%$ without excessive discarding of material. Alternatively, tracking tape thicknesses could be an effective way to monitor changes to the impedance profile of specific GDI builds within uncertainty limits. The ability to predict GDI impedance profile changes compared to the profile determined by the tape characterization method is significant; these profile changes were previously intractable and relied on tape characterization methods only because there is no method to directly measure the impedance profile of a GDI. Either approach can contribute to high-fidelity a priori forward analyses of ramp compression experiments (i.e., before obtaining a 
drive measurement), which can also reduce conservatism built into experimental designs.

Experimental diagnostics have rarely been used to explore uniformity of a dynamic compression response in the radial direction. Destructive and nondestructive evaluation methods demonstrate excellent radial uniformity of the $\mathrm{Al}-\mathrm{Cu}-\mathrm{W}-\mathrm{Ta}$ GDI. PDV traces at five different radial distances $(2-6 \mathrm{~mm})$ from the center of an Al-LiF bilayer target and with separation distances up to $13 \mathrm{~mm}$ varied by no more than $\pm 1.1 \%$ from the mean trace after applying calibrations and with a root mean square of $0.3 \%$. Bowing and side-to-side thickness variation are potential root causes for this variation, although other limits of PDV analysis that may affect response precision cannot be ruled out at this time and will require future investigation. The $95 \%$ confidence and prediction intervals developed from the five experimental traces agreed well with 1D simulations that use experimental inputs from the tape characterization and further demonstrate the use of predictive models to expedite GDI qualification.

\section{ACKNOWLEDGMENTS}

This work was performed under the auspices of the U.S. Department of Energy by Lawrence Livermore National Laboratory under contract DE-AC52-07NA27344. The authors would also like to thank Ernest Bianchi at Maryland Ceramic \& Steatite Company, Inc., for tape casting services, Renee Posadas, J. Castellanos, Joshua Ruelas, and Paul Benevento at the Lawrence Livermore National Laboratory for assistance with characterization and fabrication of the impactors, Sharon Torres and James Embree for assistance with metallography, Bob Nafzinger for target fabrication, and Michael J. Burns and Russel Oliver for assistance with the Light Gas Gun experiment. Collaboration with the Caltech Lindhurst Laboratory for Experimental Geophysics is supported by LLNL subcontract B621015.

\section{REFERENCES}

${ }^{1}$ D. Kraus, A. Ravasio, M. Gauthier, D. O. Gericke, J. Vorberger, S. Frydrych, J. Helfrich, L. B. Fletcher, G. Schaumann, B. Nagler, B. Barbrel, B. Backmann, E. J. Gamboa, S. Göde, E. Granados, G. Gregori, H. J. Lee, P. Neumayer, W. Schumaker, T. Döppner, R. W. Falcone, S. H. Glenzer, and M. Roth, Nat. Commun. 7, 10970 (2016).

2J. H. Nguyen and N. C. Holmes, Nature 427, 339 (2004).

${ }^{3}$ W. J. Nellis, Rep. Prog. Phys. 69, 1479 (2006).

${ }^{4}$ Department of Energy, Office of Science, Report of the Basic Energy Sciences Workshop on Basic Research Needs for Synthesis Science for Energy Relevant Technology, May 2-4 (2016).

${ }^{5}$ W. Grochala, R. Hoffmann, J. Feng, and N. W. Ashcroft, Angew. Chem. Int. Ed. 46, 3620 (2007).

${ }^{6}$ M. Meyers, H. Jarmakani, J. M. McNaney, M. Schneider, J. H. Nguyen, and B. Kad, J. Phys. IV France 134, 37 (2006).

7J. H. Nguyen, D. Orlikowski, F. H. Streitz, N. C. Holmes, and J. A. Moriarty, AIP Conf. Proc. 706, 1225 (2004).

${ }^{8}$ J. H. Nguyen, D. Orlikowski, F. H. Streitz, J. A. Moriarty, and N. C. Holmes, J. Appl. Phys. 100, 023508 (2006).

${ }^{9}$ H. Jarmakani, J. M. McNaney, M. S. Schneider, D. Orlikowski, J. H. Nguyen, B. Kad, and M. A. Meyers, Mater. Sci. Eng. A 463, 249 (2007).

${ }^{10}$ R. F. Smith, K. T. Lorenz, D. Ho, B. A. Remington, A. Hamza, J. Rogers, S. Pollaine, S. Jeon, Y. S. Nam, and J. Kilkenny, Astrophys. Space Sci. 307, 269 (2007).
${ }^{11}$ M. B. Aufderheide III, W. D. Brown, A. V. Hamza, H. S. Park, H. E. Martz, B. A. Remington, J. A. Rogers, S. Jeon, and Y. S. Nam, Nucl. Instrum. Methods Phys. Res. A 579, 223 (2007).

${ }^{12}$ D. C. Swift and R. P. Johnson, Phys. Rev. E 71, 066401 (2005).

${ }^{13}$ C. A. Hall, J. R. Asay, M. D. Knudson, W. A. Stygar, R. B. Spielman, T. D. Pointon, D. B. Reisman, A. Toor, and R. C. Cauble, Rev. Sci. Instrum. 72, 3587 (2001).

${ }^{14}$ D. B. Hayes, C. A. Hall, J. R. Asay, and M. D. Knudson, J. Appl. Phys. 94, 2331 (2003).

${ }^{15}$ M. D. Knudson, D. L. Hanson, J. E. Bailey, C. A. Hall, J. R. Asay, and C. Deeney, Phys. Rev. B 69, 144209 (2004).

${ }^{16}$ M. R. Baer, C. A. Hall, R. L. Gustavsen, D. E. Hooks, and S. A. Sheffield, J. Appl. Phys. 101, 034906 (2007).

${ }^{17}$ T. Ao, AIP Conf. Proc. 1195, 689 (2009).

${ }^{18}$ R. S. Hawke, D. E. Duerre, J. G. Huebel, H. Klapper, D. J. Steinberg, and R. N. Keeler, J. Appl. Phys. 43, 2734 (1972).

${ }^{19}$ R. S. Hawke, D. E. Duerre, J. G. Heubel, R. N. Keeler, and W. C. Wallace, J. Appl. Phys. 49, 3298 (1978).

${ }^{20}$ A. Pavlovskii, N. P. Kolokol'chikov, M. I. Dolotenko, and A. I. Bykov, JETP Lett. 27, 264 (1978).

${ }^{21}$ V. V. Matveev, V. V. Prut, and K. K. Khrabrov, Soviet Tech. Phys. Lett. 4, 221 (1978).

${ }^{22}$ G. A. Adadurov, V. V. Gustov, V. S. Zhuchenko, M. Y. Kosygin, and P. A. Yampol'sk, Combust. Explos. Shock Waves 9, 449 (1973).

${ }^{23}$ S. A. Bordzilovskii, V. V. Silvestrov, and V. M. Titov, Acta Astronaut. 3, 1015 (1976).

${ }^{\mathbf{2 4}}$ S. A. Bordzilovskii and N. N. Gorshkov, Combust. Explos. Shock Waves 13, 375 (1977).

${ }^{25}$ M. A. Mogilevskii, S. A. Bordzilovskii, and N. N. Gorshkov, Combust. Explos. Shock Waves 14, 794 (1978).

${ }^{26}$ G. A. Adadurov and V. I. Gol'danskii, Russ. Chem. Rev. 50, 948 (1981).

${ }^{27}$ Z. Rosenberg and Y. Partom, Appl. Phys. Lett. 41, 921 (1982).

${ }^{28}$ L. M. Barker and R. E. Hollenbachh, J. Appl. Phys. 41, 4208 (1970).

${ }^{29}$ M. Germain-Lacour and M. de Gliniasty, AIP Conf. Proc. 78, 481 (1982).

${ }^{30}$ L. M. Barker, "High-pressure quasi-isentropic impact experiments," in Shock Waves in Condensed Matter, edited by J. R. Asay, R. A. Graham, and G. K. Straub (Elsevier Science Publishers, B.V., 1984), p. 217.

${ }^{31}$ L. P. Martin, D. Orlikowski, and J. H. Nguyen, Mater. Sci. Eng. A 427, 83 (2006).

${ }^{32}$ L. P. Martin, J. R. Patterson, D. Orlikowski, and J. H. Nguyen, J. Appl. Phys. 102, 023507 (2007).

${ }^{33}$ S. J. Yep, J. L. Belof, D. A. Orlikowski, and J. H. Nguyen, Rev. Sci. Instrum. 84, 103909 (2013).

${ }^{34}$ M. Bastea and D. Reisman, AIP Conf. Proc. 955, 1169 (2007).

${ }^{35}$ H. M. Rietveld, J. Appl. Cryst. 2, 65 (1969).

${ }^{36}$ A. Hewat, W. I. F. David, and L. van Eijck, J. Appl. Cryst. 49, 1394 (2016).

${ }^{37}$ P. A. Rigg, M. D. Knudson, R. J. Scharff, and R. S. Hixson, J. Appl. Phys. 116, 033515 (2014).

${ }^{38}$ C. R. Noble, A. T. Anderson, N. R. Barton, J. A. Bramwell, A. Capps, M. H. Chang, J. J. Chou et al., Ale3d: An Arbitrary Lagrangian-Eulerian Multi-Physics Code, LLNL-TR-732040 (Lawrence Livermore National Laboratory, Livermore, CA, 2017).

${ }^{39}$ D. Steinberg, Equation of State and Strength Properties of Selected Materials (Lawrence Livermore National Laboratory, Livermore, CA, 1996).

${ }^{40} \mathrm{~J}$. P. Kelly and O. A. Graeve, "Effect of powder characteristics on nanosintering," in Sintering Mechanisms of Convention, Nanodensification, and Field Assisted Processes, edited by R. Castro and K. van Benthem (Springer-Verlag, Berlin, 2013), p. 57.

${ }^{41}$ J. K. MacKenzie, Proc. Phys. Soc. B 63, 2 (1950).

${ }^{42}$ G. A. Lushnikov, I. G. Popova, V. N. Mustafina, and V. Y. Tsarev, Refractories 15, 325 (1974).

${ }^{43}$ Q. Fan, J. Takatsubo, and S. Yamamoto, J. Appl. Phys. 86, 4023 (1999).

${ }^{44}$ K. V. Horoshenkov, D. C. Hughes, and A. Cwirzen, Appl. Acoust. 64, 197 (2003). 
${ }^{45}$ S. S. Sekoyan, V. R. Shlegel, S. S. Batsanov, S. M. Gavrilkin, K. B. Poyarkov, A. A. Gurkov, and A. A. Durov, J. Appl. Mech. Tech. Phys. 50, 646 (2009).

${ }^{46}$ G. S. Schajer and C. O. Ruud, "Overview of residual stresses and their measurement," in Practical Residual Stress Measurement Methods, edited by G. S. Schajer (Wiley, New York, 2013), p. 1.

${ }^{47}$ D. E. Bray, "Ultrasonics," in Practical Residual Stress Measurement Methods, edited by G. S. Schajer (Wiley, West Sussex, 2013), p. 259.
${ }^{48}$ W. D. Kingery, H. K. Bowen, and D. R. Uhlmann, Introduction to Ceramics (Wiley, New York, 1976), p. 773.

${ }^{49} \mathrm{~J}$. F. Shackelford and W. Alexander, Materials Science and Engineering Handbook (CRC Press, Boca Raton, FL, 2001), p. 55.

${ }^{50}$ R. T. Krone, L. P. Martin J. R. Patterson, D. Orlikowski, and J. H. Nguyen, Mater. Sci. Eng. A 479, 300 (2008).

${ }^{51}$ T. J. Vogler, T. Ao, and J. R. Asay, Intl. J. Plast. 25, 671 (2009). 